\title{
Estimation of Ground Vertical Displacement in Landslide Prone Areas Using PS-InSAR. A Case Study of Bududa, Uganda
}

\author{
Brian Makabayi, Moses Musinguzi, John Richard Otukei \\ Department of Geomatics and Land Management, Makerere University, Kampala, Uganda \\ Email: mak2brian@gmail.com
}

How to cite this paper: Makabayi, B., Musinguzi, M. and Otukei, J.R. (2021) Estimation of Ground Vertical Displacement in Landslide Prone Areas Using PSInSAR. A Case Study of Bududa, Uganda. International Journal of Geosciences, 12, 347-380.

https://doi.org/10.4236/ijg.2021.124019

Received: February 26, 2021

Accepted: April 23, 2021

Published: April 26, 2021

Copyright $\odot 2021$ by author(s) and Scientific Research Publishing Inc. This work is licensed under the Creative Commons Attribution International License (CC BY 4.0).

http://creativecommons.org/licenses/by/4.0/

(c) (i) Open Access

\begin{abstract}
Estimation of ground displacement in landslide susceptible regions is very critical to understanding how landslides develop. The knowledge of ground displacement rates and magnitudes helps plan for the safety of the people and infrastructure. The early detection of landslides in Bududa is still a challenge due to the limited technology, hard to access, and a need for an affordable technique that can monitor a wide area continuously. In recent studies, the use of Persistent Scatterer Interferometry Synthetic Aperture Radar (PS-InSAR) has provided vital information on landslide monitoring through the measurement of ground displacement. In this study, Synthetic Aperture Radar (SAR) band C series of Sentinel 1-A and 1-B Satellite images were acquired between 2019 and 2020 along ascending and descending orbit paths. The Line of Sight Sight (LOS) displacement was determined for both satellite tracks, and then the LOS displacement was projected to the vertical direction. The PS-InSAR derived vertical displacement was then compared with GPS vertical displacement magnitudes over three GPS stations in the area. It was observed that vertical displacement velocity reached $20 \mathrm{~cm} / \mathrm{yr}$ in Mountain Elgon. This displacement rate showed that there are points in the region that are highly unstable. The displacement velocity and magnitude in Bududa reached $6 \mathrm{~cm} / \mathrm{yr}$ and $13 \mathrm{~cm}$ in two years. This rate and magnitude showed that Bududa is highly unstable compared with displacement velocities and magnitudes in landslide susceptible areas globally. The displacement was generally subsidence over the observation period. The vertical displacement estimated by PS-InSAR was comparable with GPS based on the estimated RMSE. The vertical displacement was highest at slopes between $32^{\circ}$ and $60^{\circ}$ and lowest between $0^{\circ}$ and $9^{\circ}$. The vertical ground displacement was highly correlated with the rainfall that was received. The soil texture in Bududa has high clay content, with clay layering hence low drainage rates, field capacity, saturation and bulk density. It was observed that ground displacement was highly influ-
\end{abstract}


enced by slope, rainfall and soil texture. Displacement could be estimated in three dimensions using PS-InSAR in the future if sufficient SAR images in ascending and descending tracks are made available with significantly different geometries. This would add to the knowledge of displacement patterns in the east and north directions at a large spatial scale.

\section{Keywords}

Bududa, Landslides, PS-InSAR, Vertical Displacement

\section{Introduction}

Landslides are one of the most devasting natural disasters in the world. They are responsible for the destruction of property, the environment and human life. Landslides happen after the slope fails; this could be through debris flow, mudflows, human activity or rock falls. Landslide can also occur through different movements, for example, spreads, falls, topples, slides or flows. The combination of all these factors to cause movement is not uncommon [1]. On the other hand, the landslide triggering factors majorly include rainfall, river overflow, earthquakes, volcanic eruptions and slope undercuts.

The measurement of ground displacement is crucial in the monitoring of landslides [2]. It is essential because it gives insight into how landslides form and build before a failure happens. Monitoring surface displacement over a large area is vital to identify unstable areas potentially at risk of landslides. However, this process has challenges to achieve due to the landslide formation process's complex nature [3]. Landslide inventories today require documentation of the rate at which slopes are sliding hence making the need for information on displacement critical [4] [5].

The Interferometric Synthetic Aperture Radar (InSAR) technique has been widely applied in monitoring ground displacement in landslide susceptible areas due to its ability to cover large areas. It has a high spatial and temporal resolution, and it works all day, both at night and day and through all weather conditions. Furthermore, the traditional InSAR technique estimates ground displacement in the order of $\mathrm{dm} / \mathrm{yr}$ [6]-[11]. Whereas the more advanced InSAR algorithms which are based on a stack of SAR images, that is, the small baseline subset (SBAS) InSAR and Persistent Scatterers (PS) can determine even slower displacement reaching $\mathrm{mm} / \mathrm{yr}$.

The PS is an advanced InSAR technique that can estimate ground displacement at millimetre level [12]. Conventional InSAR can estimate surface displacement, but it is affected by temporal decorrelation due to vegetation. The temporal decorrelation limits the application of conventional InSAR measurement of surface displacement of natural terrains. Conventional InSAR is additionally affected by phase delay that results from atmospheric constituents. These atmospheric constituents are difficult to remove from interferograms, especially when conventional InSAR is used [13]. The PS-InSAR technique, on the other 
hand, utilises a large set of SAR images to overcome the temporal decorrelation and phase delay limitations of conventional InSAR. The Persistent Scatterers used are pixels with stable amplitude and phase throughout all the datasets and monitor periods. These pixels may be buildings in the area, corner cube reflectors, or bear ground. The stable pixels are used by the PS-InSAR technique to determine and remove atmospheric and topographic errors from interferograms. After the removal of atmospheric and topographic errors from the interferograms, the differential interferograms comprise only the residual phase that results from surface deformation [14]. The PS-InSAR technique has been proven to estimate surface displacement in landslide-prone areas [15]-[28].

Bududa has been observed to experience significant displacement in the vertical direction compared to the horizontal. In the absence of a technique that estimates displacement reliably in all directions and at many points. A technique that estimates displacements reliably in the vertical direction and at many points should be considered. InSAR is such a technique that estimates ground displacement in the vertical direction more reliably than the horizontal and at more points than GPS. This advantage is attributed to the ascending and descending trajectory of the SAR satellites [29]. InSAR, however, does not directly measure displacement in the vertical direction but the Line of Sight (LOS); therefore, it requires projection of the LOS displacement to the vertical direction [30]. Several algorithms have been developed to ensure that the projection to both the vertical and horizontal directions is reliable enough to achieve accuracy comparable to Global Positioning Systems (GPS) and Levelling [28] [30]. In this study, we employ a technique where a combination of ascending and descending satellite tracks of significantly different geometrical properties are used to derive vertical displacement [30]. We here, however, put emphasis on the vertical displacement that is well estimated by InSAR and used PS-InSAR to derive displacement points in the vertical, which points are more comparable with GPS points in contrast to if we had used Small Baseline Subset (SBAS) advanced InSAR algorithm. However, this approach is affected by several factors beyond the technical limitation of the formulae used. These include the number of ascending and descending satellites available, atmospheric and topographic artefacts. We use a significant number of ascending and descending satellites with suitable geometrical properties. Use high temporal imagery with short baseline lengths and a Digital Elevation Model (DEM) of a fair resolution. We then compare the retrieved vertical displacement with GPS measurements to assess InSAR derived vertical displacements' reliability. Additionally, derived vertical displacement is compared with slope, rainfall and soil characteristics to determine the influence of these on ground displacement.

\section{Data and Methods}

\subsection{Study Area}

This study was undertaken in Bududa district because of the frequency of landslides 
experienced. Bududa district is a relatively new district created from former Manjiya County in 2006 ; it stretches from $34.26^{\circ}$ West to $34.54^{\circ}$ East and $0.96^{\circ}$ South to $1.12^{\circ}$ North and lies on the southwest slopes of Mountain Elgon. Its length from south to north is $14.9 \mathrm{~km}$, and the west to east width is $29.6 \mathrm{~km}$. The average precipitation in Bududa is above $1500 \mathrm{~mm}$ of rainfall per year and is bi-modal with two dry spells, one in July and the other from December to February. It has a long-wet season running from March to June, and a short-wet season from August to November; the highest rainfall in May. The high altitude of the District highly controls the rainfall pattern. It is, however, not uncommon for the rainfall patterns to vary due to climate change. Additionally, the rainfall intensity has been observed to vary due to the Indian Ocean Dipole (IOD) phenomenon in recent days.

A about a quarter of the study area is protected and covered by Mountain Elgon national park. The District has about twenty-four (24) small rivers flowing through it from the Mountain Elgon peak, through the cultivated and degraded habited slopes and valleys to river Manafwa and draining into Lake Kyoga, as shown in Figure 1.

The District has high altitude variation ranging from 1250 to $2850 \mathrm{~m}$. The altitude rises in the east to 3000 and $4000 \mathrm{~m}$ at the peak of the Mountain, as shown in Figure 1. The District generally has steep slopes. The District's population growth rate is high compared to the national approximated at $3.8 \%$, which has led to increased deforestation and soil degradation.

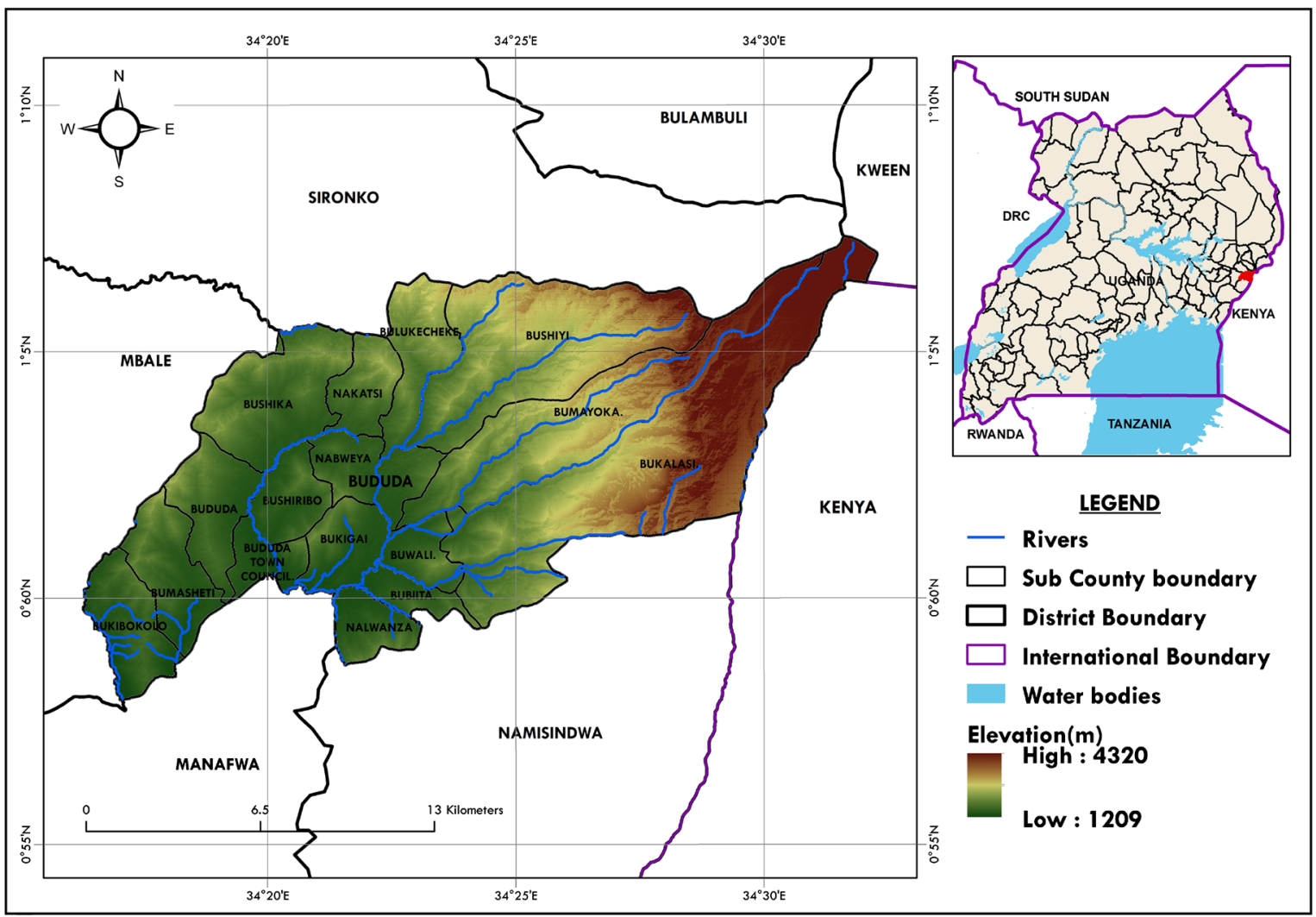

Figure 1. Location of Bududa district, it's sub-counties, rivers, elevation and the neighbouring districts. Source [31]. 
The predominant soil type classified by the Food Agriculture Organization (FAO) is Nitisols with Luvisols, Gleysols and Agric Ferralsols distributed in other District parts. The centre of the study area consists of iron-rich Rhodic Nitisols red in colour. These are permeable to water and plant roots limiting water run-off due to magnetite and hematite constituents. These properties make such soils very stable and hence experience minor displacement and landslides due to the high cohesion resulting from calcium carbonate ingredients. North and west of the District are where Lixisols, Cambisols, Nitisols and Acrisols soils are observed with many shear planes within the ground 0.2 to $2 \mathrm{~m}$ and the parent rock. These are observed at the clay layering horizons and cause surface cracks that widen with an increase in rainfall. The east consists of Ferralsols, Lixisols, Gleysols and Acrisols, which deform under steep slopes and heavy rain due to excessive soil degradation.

\subsection{InSAR Datasets}

The Copernicus Sentinel-1 C band Synthetic Aperture Radar (SAR) images from the European Commission (EC) and European Space Agency (ESA) initiative were used in the study. The Sentinel-1A and -1B twin spaceborne satellite images were used. Particularly, the Sentinel-1 Terrain Observation with Progressive Scan (TOPS) mode was used because it covers a wide area and the revisit period is short (12 days globally and 6 days in Europe). The TOPS mode imagery is well suited for InSAR applications, according to [32]. TOPS mode obtains data in three sub-swaths which cover $250 \mathrm{~km}$, and the ground range cell size is $5 \times 20 \mathrm{~m}$. TOPs mode attains uniform distributed target ambiguity ratio and signal-to-noise ratio electronically steering the radar beam backwards to forwards in an azimuth direction.

Additionally, it steers the beam in a range direction like in normal ScanSAR mode [33]. Each sub-swath comprises bursts, where each burst is an independent Single Look Complex (SLC) image. The bursts in each sub-swath are arranged in an azimuth-time domain, having black lines separating these bursts. Furthermore, Sentinel-1 data is free and can be accessed via different data hubs, for example, Copernicus Open Access Hub. Data processing has to be done on the Sentinel data sets before the application of PS-InSAR. The data processing mainly involves extraction of the sub-swath covering the area studied, a process called TOPS splitting. The removal of black strips is done, which separates the bursts by moving a window averaging filter through the bursts, a process called TOPS deburst [32].

We processed two independent sets of Sentinel-1A and 1B images acquired along the descending and ascending orbits (Track 130 [Asc] and 50 [Dsc]) to be able to map the surface displacement of slow-moving landslides in Bududa as shown in Table 1 and Table 2. On the ascending track 130, we computed 55 interferograms, and on the descending track 50, we formed 53 pairs as shown in Table 1 and Table 2. We used individual interferograms with high coherence for each track. We discarded interferograms affected by temporal decorrelation and 
atmospheric noise in the mountainous areas. It was done using visual inspection of the interferograms. The PS technique used based on a single master image selected using amplitude and phase criteria for the selection of PSs. This technique does not optimally work when the coherence is low and may lead to low PS density. That is why we had different PS density for the ascending and descending tracks in this study, as shown in Table 1.

The process began with selecting $4^{\text {th }}$ of January 2020 and $5^{\text {th }}$ of January 2020 as the master images for the ascending and descending tracks as shown in Figure 2 and Figure 3. In the ascending and descending images, the master image and all the remaining 55 and 53 slave images were coregistered, respectively. The coregistration process aligned the slave images with the master images at sub-pixel level accuracy. It ensured that backscatter information could be retrieved from the same ground targets. After completing the co-registration process, interferograms were generated through a phase difference between each slave and master image.

Table 1. Data coverage from each track used in the study.

\begin{tabular}{ccccccc}
\hline Track & Sensor & Geometry & $\begin{array}{c}\text { Time } \\
\text { Interval }\end{array}$ & $\begin{array}{c}\text { Incidence } \\
\text { Angle }\left(^{\circ}\right)\end{array}$ & $\begin{array}{c}\text { Interferograms } \\
\text { Used }\end{array}$ & $\begin{array}{c}\text { Density } \\
\text { PS/Km }\end{array}$ \\
\hline T130 & SENTINEL 1 & Ascending & $2019-2020$ & $30.5-35.5$ & 55 & $\sim 53$ \\
T50 & SENTINEL 1 & Descending & $2019-2020$ & $40.4-45.5$ & 53 & $\sim 24$ \\
\hline
\end{tabular}

Table 2. Track 13056 SAR images [Asc] and Track 5054 SAR images [Dsc].

\begin{tabular}{|c|c|}
\hline Sentinel-1A Stack & Sentinel-1B Stack \\
\hline S1A_IW_SLC_1SDV_20190109 & S1B_IW_SLC_1SDV_20190110 \\
\hline S1A_IW_SLC_1SDV_20190121 & S1B_IW_SLC_1SDV_20190122 \\
\hline S1A_IW_SLC_1SDV_20190202 & S1B_IW_SLC_1SDV_20190203 \\
\hline S1A_IW_SLC_1SDV_20190214 & S1B_IW_SLC_1SDV_20190215 \\
\hline S1A_IW_SLC_1SDV_20190226 & S1B_IW_SLC_1SDV_20190227 \\
\hline S1A_IW_SLC_1SDV_20190310 & S1B_IW_SLC_1SDV_20190311 \\
\hline S1A_IW_SLC_1SDV_20190322 & S1B_IW_SLC_1SDV_20190323 \\
\hline S1A_IW_SLC_1SDV_20190403 & S1B_IW_SLC_1SDV_20190404 \\
\hline S1A_IW_SLC_1SDV_20190415 & S1B_IW_SLC_1SDV_20190416 \\
\hline S1A_IW_SLC__1SDV_20190509 & S1B_IW_SLC_1SDV_20190428 \\
\hline S1A_IW_SLC__1SDV_20190521 & S1B_IW_SLC_1SDV_20190510 \\
\hline S1A_IW_SLC_1SDV_20190602 & S1B_IW_SLC_1SDV_20190522 \\
\hline S1A_IW_SLC_1SDV_20190614 & S1B_IW_SLC_1SDV_20190603 \\
\hline S1A_IW_SLC_1SDV_20190626 & S1B_IW_SLC_1SDV_20190615 \\
\hline S1A_IW_SLC_1SDV_20190708 & S1B_IW_SLC_1SDV_20190627 \\
\hline S1A_IW_SLC_1SDV_20190720 & S1B_IW_SLC_1SDV_20190709 \\
\hline S1A_IW_SLC_1SDV_20190801 & S1B_IW_SLC_1SDV_20190721 \\
\hline S1A_IW_SLC_1SDV_20190813 & S1B_IW_SLC_1SDV_20190826 \\
\hline
\end{tabular}




\section{Continued}

S1A_IW_SLC_1SDV_20190906

S1A_IW_SLC_1SDV_20190918

S1A_IW_SLC_1SDV_20191012

S1A_IW_SLC_1SDV_20191024

S1A_IW_SLC_1SDV_20191105

S1A_IW_SLC_1SDV_20191117

S1A_IW_SLC_1SDV_20191129

S1A_IW_SLC_1SDV_20191211

S1A_IW_SLC_1SDV_20191223

S1A_IW_SLC_1SDV_20200104

S1A_IW_SLC_1SDV_20200116

S1A_IW_SLC_1SDV_20200128

S1A_IW_SLC_1SDV_20200209

S1A_IW_SLC_1SDV_20200221

S1A_IW_SLC_1SDV_20200304

S1A_IW_SLC_1SDV_20200316

S1A_IW_SLC_1SDV_20200328

S1A_IW_SLC_1SDV_20200409

S1A_IW_SLC_1SDV_20200421

S1A_IW_SLC_1SDV_20200421

S1A_IW_SLC_1SDV_20200503

S1A_IW_SLC_1SDV_20200515

S1A_IW_SLC_1SDV_20200527

S1A_IW_SLC_1SDV_20200608

S1A_IW_SLC_1SDV_20200620

S1A_IW_SLC_1SDV_20200702

S1A_IW_SLC_1SDV_20200714

S1A_IW_SLC_1SDV_20200726

S1A_IW_SLC_1SDV_20200807

S1A_IW_SLC_1SDV_20200819

S1A_IW_SLC_1SDV_20200831

S1A_IW_SLC_1SDV_20200912

S1A_IW_SLC_1SDV_20200924

S1A_IW_SLC_1SDV_20201006

S1A_IW_SLC_1SDV_20201018

S1A_IW_SLC_1SDV_20201030

S1A_IW_SLC_1SDV_20201111

S1A_IW_SLC_1SDV_20201123
S1B_IW_SLC_1SDV_20190907

S1B_IW_SLC_1SDV_20190919

S1B_IW_SLC_1SDV_20191001

S1B_IW_SLC_1SDV_20191013

S1B_IW_SLC_1SDV_20191025

S1B_IW_SLC_1SDV_20191106

S1B_IW_SLC_1SDV_20191118

S1B_IW_SLC_1SDV_20191130

S1B_IW_SLC_1SDV_20191224

S1B_IW_SLC_1SDV_20200105

S1B_IW_SLC_1SDV_20200117

S1B_IW_SLC_1SDV_20200129

S1B_IW_SLC_1SDV_20200210

S1B_IW_SLC_1SDV_20200222

S1B_IW_SLC_1SDV_20200317

S1B_IW_SLC_1SDV_20200329

S1B_IW_SLC_1SDV_20200410

S1B_IW_SLC_1SDV_20200422

S1B_IW_SLC_1SDV_20200504

S1B_IW_SLC_1SDV_20200516

S1B_IW_SLC_1SDV_20200528

S1B_IW_SLC_1SDV_20200609

S1B_IW_SLC_1SDV_20200621

S1B_IW_SLC_1SDV_20200703

S1B_IW_SLC_1SDV_20200715

S1B_IW_SLC_1SDV_20200727

S1B_IW_SLC_1SDV_20200808

S1B_IW_SLC_1SDV_20200820

S1B_IW_SLC_1SDV_20200901

S1B_IW_SLC_1SDV_20200913

S1B_IW_SLC_1SDV_20200925

S1B_IW_SLC_1SDV_20201007

S1B_IW_SLC_1SDV_20201019

S1B_IW_SLC_1SDV_20201031

S1B_IW_SLC_1SDV_20201112

S1B_IW_SLC_1SDV_20201124 


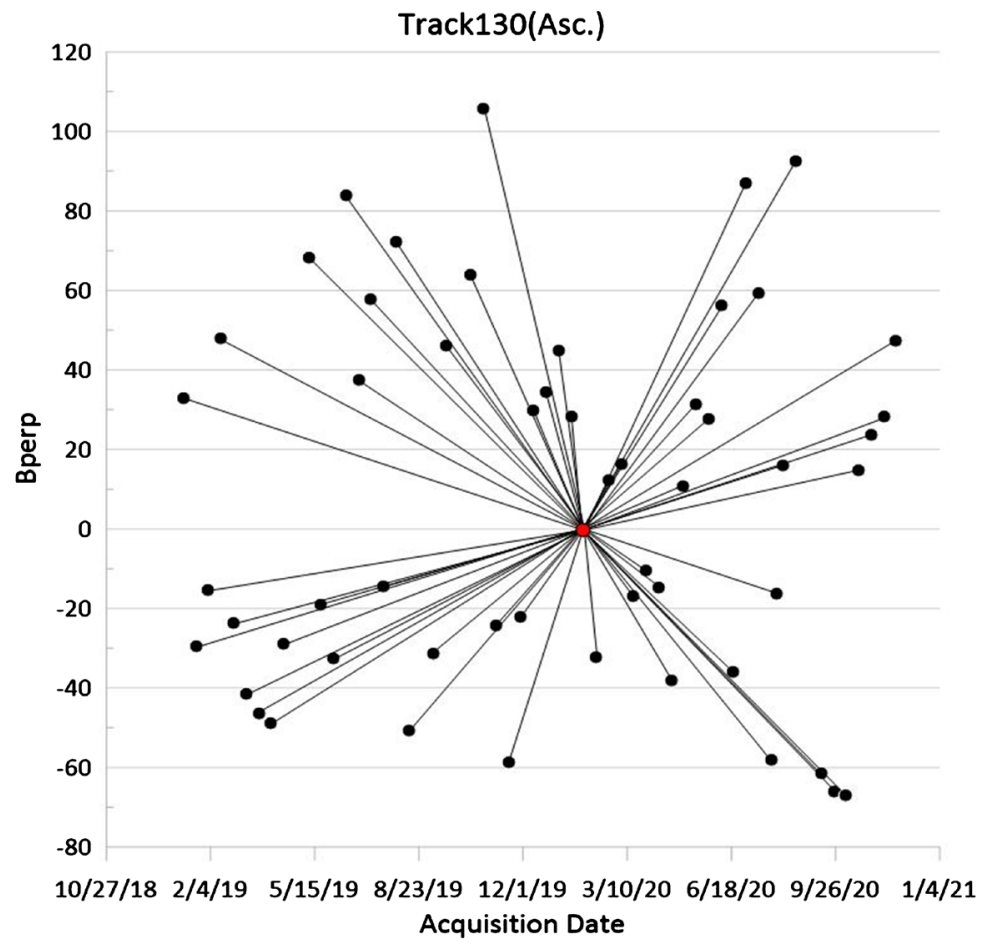

Figure 2. The baseline versus the time plots for Sentinel ascending track 130 used in this study. The black dots represent image acquisition time, and the red dot, the master image used as the reference. The black lines connect interferogram pairs.

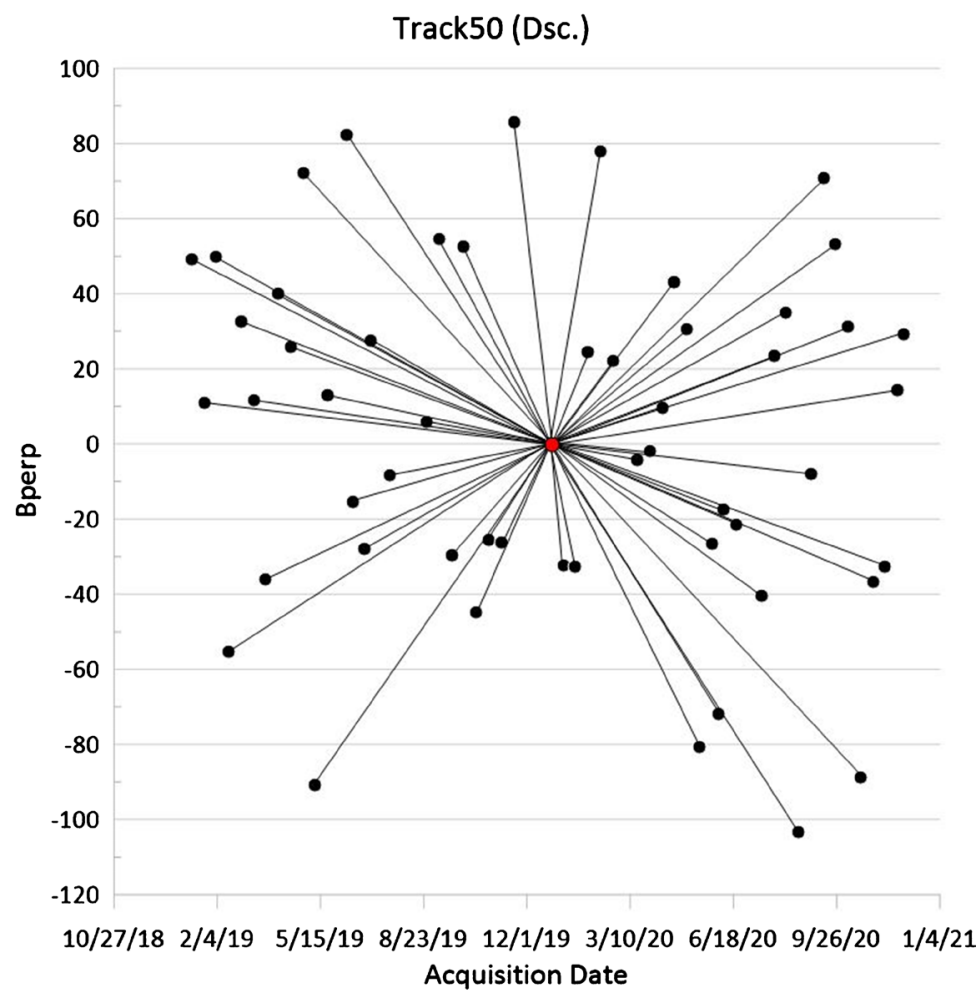

Figure 3. The baseline versus the time plots for Sentinel descending track 50 used in this study. The black dots represent image acquisition time, and the red dot, the master image used as the reference. The black lines connect interferogram pairs. 


\subsection{PS-InSAR Processing Methodology}

The topographic contribution to each interferogram's radar phase was eliminated using the Shuttle Radar Topography Mission (SRTM) 3-arcsecond digital elevation model [34]. The interferograms were then geocoded to align them in the correct geographical position for interpretation purposes. The initial selection of PS points was based on noise characteristics and amplitude analysis, as discussed by [35]-[41]. These PSs can only be estimated after eliminating atmospheric artefacts, DEM errors, deformation due to terrain and orbital ramps. Because we need targets with low geometric and temporal decorrelation, pixels with stable amplitudes should be selected.

A subset of pixels from the Persistent Scatterer Candidates (PSC) was selected as final PSs after determining the phase stability. The Amplitude Dispersion Index $\left(D_{A}\right)$ was used to select the amplitude stable pixels [39] [42] [43].

$$
D_{A}=\frac{\sigma_{A}}{\mu_{A}}
$$

where, $\sigma_{A}$ is the temporal deviation and $\mu_{A}$ the temporal mean for each pixel. For low values of the Amplitude Dispersion Index, reaching 0.25, the amplitude and phase dispersion were in good agreement [39]. For Persistent Scatterer Candidates in phase analysis, the Amplitude Dispersion Index was used, where a threshold of 0.4 was used to select a large number of pixels. Given a PSC $(x)$ in the $i^{\text {th }}$ interferogram that has been corrected for topographic errors, the interferometric phase can be computed as [12] [44]:

$$
\phi_{\mathrm{int}, x, j}=W\left\{\phi_{\text {def }, x, i}+\phi_{a, x, i}+\phi_{\mathrm{orb}, x, i}+\phi_{\varepsilon, x, i}+n_{x, i}\right\}
$$

where, $\phi_{\text {def }, x, i}$ is the surface deformation, $\phi_{a, x, i}$ the atmospheric phase delay, $\phi_{o r b, x, i}$ the phase due to orbital errors, $\phi_{\varepsilon, x, i}$ phase due to look angle errors and $n_{x, i}$ noise. $W$ is the wrapped operator of the interferogram. The spatially correlated phase contributions from surface displacement, atmosphere and orbit were estimated using a band-pass filter in the spatial domain. On the other hand, the look angle was estimated by correlating it with the perpendicular component of the baseline.

The temporal coherence $(\gamma)$ of the PSCs was then computed to finally estimate phase noise in the interferograms using Equation (3) [12] [44].

$$
\gamma_{x}=\frac{1}{N}\left|\sum_{i=1}^{N} \exp \left\{\phi_{\mathrm{int}, x, i}-\bar{\phi}_{\mathrm{int}, x, i}-\Delta \hat{\phi}_{\varepsilon, x, i}\right\}\right|
$$

where $\gamma_{x}$ is the temporal coherence, $N$ is the number of interferograms, $\bar{\phi}_{\mathrm{int}, x, i}$ the spatially correlated components and $\Delta \hat{\phi}_{\varepsilon, x, i}$ the look angle error. The PSC with high temporal coherence was selected as the next PSC rejecting the remaining PSCs. This selected PSC had the surface displacement, atmospheric phase delay, phase due to orbital errors and phase due to look angles re-estimated iteratively, dropping PSCs based on the criteria in Equation (3) until the noise term in Equation (2) was determined. This was done until the temporal coherence of the PSC dominated the noise that remained in the interferogram. 
The final Persistent Scatterers (PS) was selected from the PSCs using the Amplitude Dispersion Index and temporal coherence. To achieve this, the Persistent Scatterer probability was calculated for the PSC. Finally, PSs dominated by scatterers in pixels neighbouring and those persistent in some particular interferograms were rejected. The pixels that remained were selected as the final Persistent Scatterers for surface displacement estimation [44]. The interferometric phase difference between adjacent PS pixels would at times be greater than $\pi$ due to spatially uncorrelated component of the look angle error.

Before phase unwrapping, the look angle error contribution from the slave and master images was estimated. The 3D phase unwrapping technique was used to unwrap the wrapped phase, as shown in Figure 4. The 3D unwrapping took

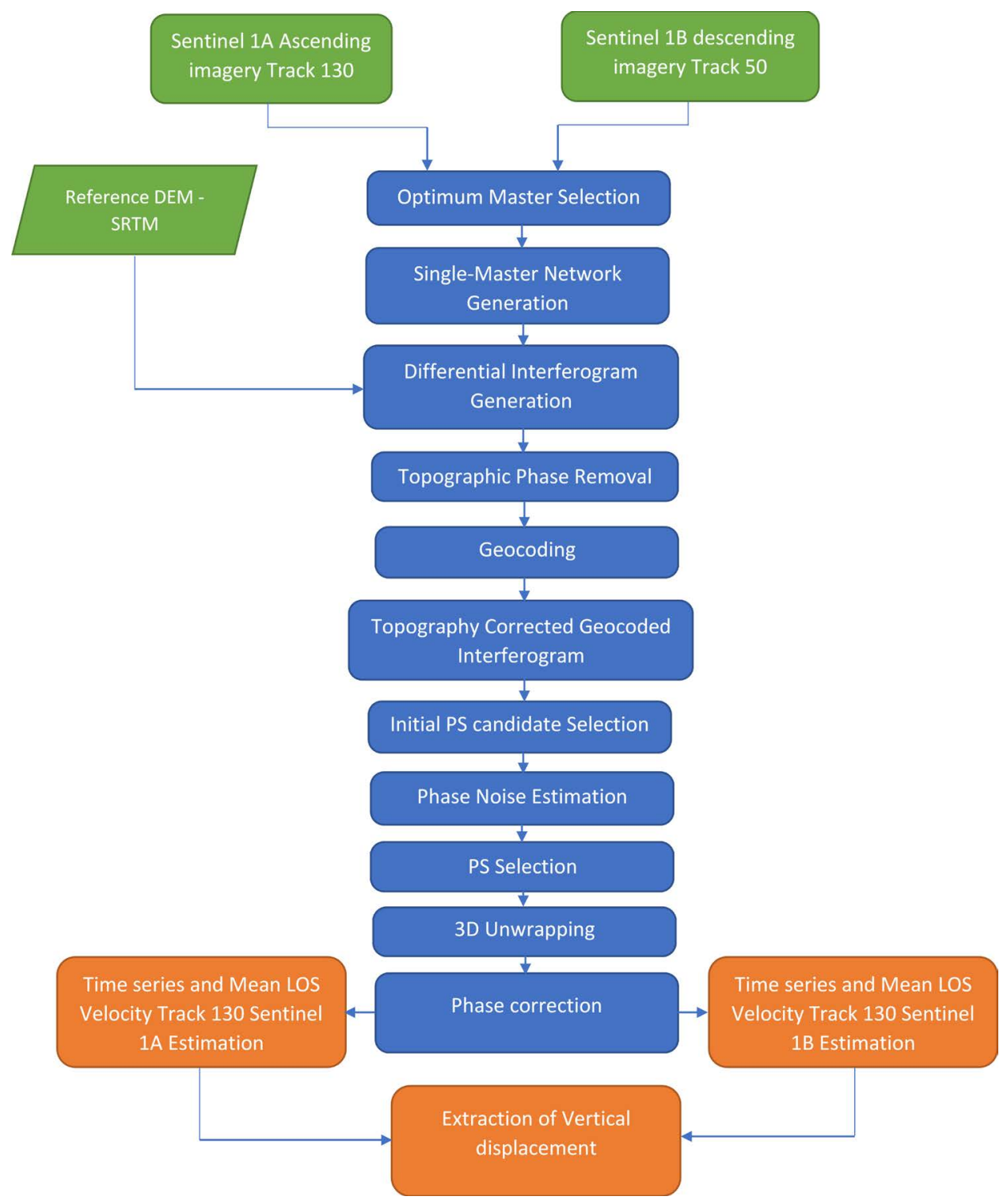

Figure 4. The flow chart showing the methodology followed during the PS-InSAR processing. Outputs are displayed for each processing step and, finally, the Time series, mean LOS velocity and vertical displacement. 
two dimensions in the spatial domain and one dimension in the time domain. To ensure that the phase unwrapping was accurate, the displacement between a PS pixel and one of the neighbouring PS had to be less than half the antenna wavelength. The LOS displacement was then extracted for the ascending and descending satellite tracks.

The vertical displacement was finally estimated using Equation (4). Ascending and descending tracks with different incidence and azimuth angles provides different perspectives on ground movement, and this is a base to extract vertical deformation from InSAR processing [45]. The vertical velocities and time-series were recovered, assuming that there was no movement in the west-east direction [45]. Only two of the three components could be retrieved. The PS-InSAR LOS displacement of the ascending and descending tracks was decomposed into east-west and vertical components. It was assumed that the north-south deformation was negligible. This is due to the near-polar orbits that SAR satellites have, this produces low sensitivity to the north-south deformation component. The InSAR LOS velocity for the ascending and descending tracks were first transformed into the same reference frame using a stable reference area before the decomposition process. The LOS velocity was decomposed into the horizontal and vertical deformation components based on the local incidence angle of the satellite using Equation (4). The Vertical deformation velocities and timeseries for all the estimated PSs were extracted. Emphasis was put on the vertical deformation that was estimated reliably as discussed earlier in the introduction section.

$$
\left(\begin{array}{c}
v_{a s c} \\
v_{d s c}
\end{array}\right)=\left(\begin{array}{l}
\cos \theta_{a s c}-\cos \alpha_{a s c} \sin \theta_{a s c} \\
\cos \theta_{d s c}-\cos \alpha_{d s c} \sin \theta_{d s c}
\end{array}\right)\left(\begin{array}{c}
v_{v e r} \\
v_{h o r}
\end{array}\right)
$$

where $v_{a s c}$ and $v_{d s c}$ the velocity of the ascending and descending tracks, $\theta_{a s c}$ and $\theta_{d s c}$ local incidence angles of the ascending and descending tracks, $\alpha_{a s c}$ and $\alpha_{d s c}$ satellite heading in the ascending and descending tracks $v_{v e r}$ and $v_{h o r}$ the velocity in the vertical and horizontal directions.

\section{Results and Discussions}

\subsection{Results}

\subsubsection{InSAR-Derived Mean Velocity Maps}

The mean vertical velocity map was determined for the whole of Mountain Elgon, as shown in Figure 5. It exploits the advantage of InSAR where displacements can be determined over a larger area compared to other ground displacement measurement techniques like GPS. The results showed that the vertical displacement velocity in Mountain Elgon reached $20 \mathrm{~cm} / \mathrm{yr}$, a high displacement posing a danger to surrounding communities.

It was not possible to estimate Ground displacement using PS-InSAR in the heavily vegetated areas of Bududa due to high temporal decorrelation, as shown in Figure 5. Ground displacement was instead estimated in less dense vegetated areas where PS-InSAR was able to determine sufficient PSs. Even if the displacement 

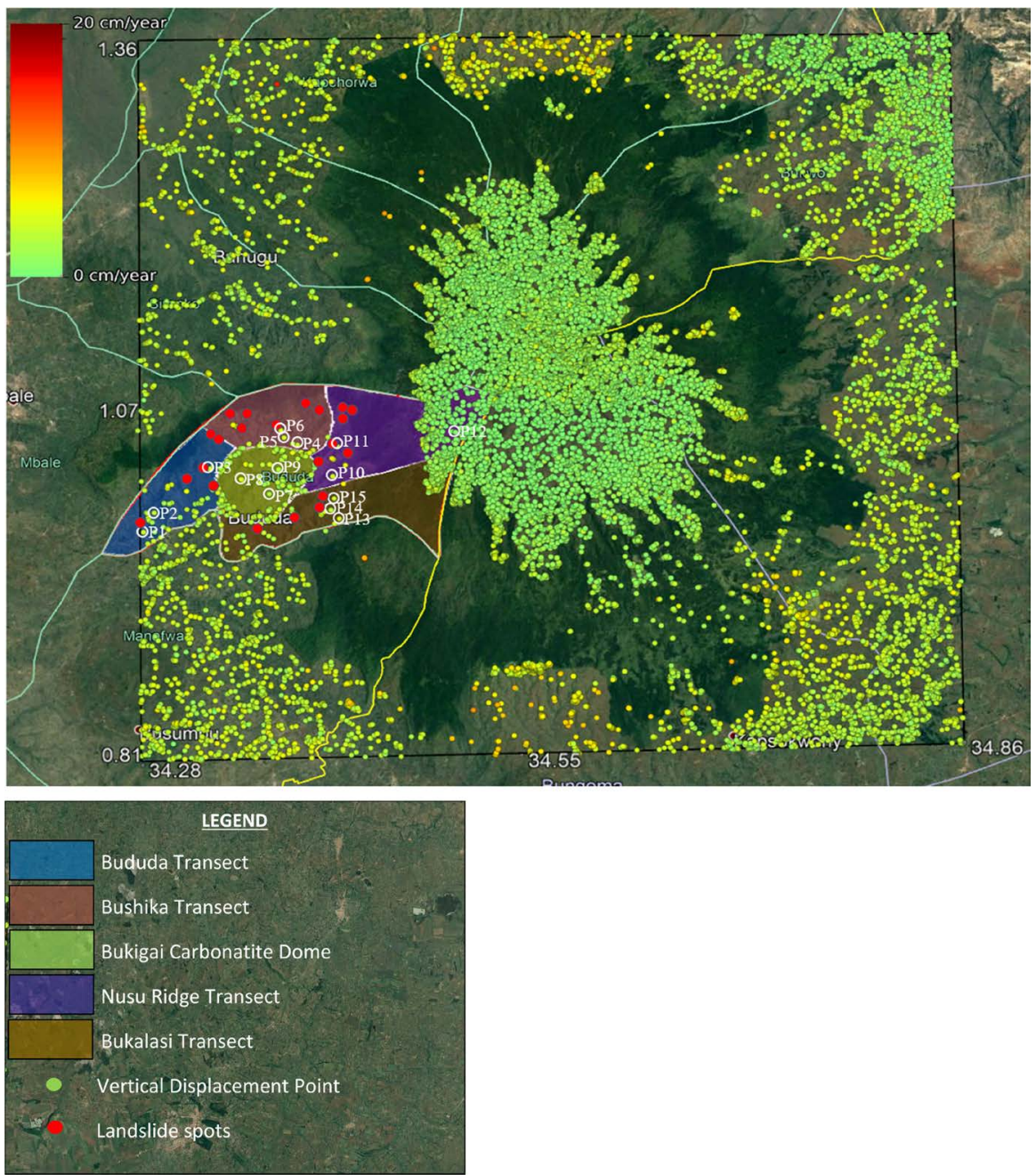

Figure 5. Displacement points estimated from PS-InSAR from 2019 to 2020 for areas around mountain Elgon and Bududa district-highlighted in Blue is Bududa trasenct, marron is Bushika, Green is Bukigai Carbonatite dome, Purple the Nusu ridge and Yellow Bukalasi. These areas generally have similar soil, topographic characteristics, land use land cover and climatic conditions.

velocity in Mountain Elgon was high, reaching $20 \mathrm{~cm} / \mathrm{yr}$, in the area of interest, Bududa, the highest displacement velocity was $6 \mathrm{~cm} / \mathrm{yr}$ as observed from the detailed vertical displacement point time-series shown in Figures 6-10. This high displacement velocity is responsible for the cracks seen throughout the District widening each day and further culminating into landslides. To further analyse the displacements in Bududa, the District was divided into five Transects, that is Bududa located in the west of the District, Bushika in the north, Nusu Ridge in the northeast, Bukalasi in the south and south-east, and Bukigai carbonatite dome in the central see Figure 5. These transects are sample units that have been used by priori researchers who have studied soil characteristics in Bududa to inform the landslides process [46] [47] [48] [49]. These five transects have different soils and topographic characteristics which influence ground displacement. The Bududa and Bushika transects are comprised mainly of Cambisols, Nitisols, 
Acrisols and Lixisols. They both have high clay content but Bushika has been observed to have more landslide incidences than Bududa. However, the soils in Bududa and Bushika do not show signs of any horizon stratification or water stagnation properties whose characteristics are of areas susceptible to landslides. The majority of Bushika and Bududa are of lower terrain compared to the east of the District. However, Bushika and the upper parts of Bududa have a higher elevation than the lower parts of the Bududa transect. These lower parts of Bududa, which Bukibokolo sub-county covers, have rarely experienced landslides in the past and experienced minimal displacement in this study.

Landslides in Nusu and Bukalasi transects are frequent. The landslides that occur here are shallow and translational compared to the landslides in Bushika and Bududa transects, deep and rotational. The landslides in Nusu and Bukalasi have been attributed to slope concavity, high elevation, slope cultivation, and slopes' terracing. These areas experienced high displacement. Areas in Nusu and Bukalasi at lower slopes have not had landslides reported there, which was justified with minimal displacement. In the high elevation parts of Nusu and Bukalasi, the soils have high infiltration rates; hence water flows very fast deep into the lower layers and stagnates at points of high clay content thus high displacement and landslides.

The soils in the Bukigai carbonatite dome have high clay content above $30 \%$ and less than $20 \%$ change in the clay content above at least $12 \mathrm{~cm}$ in the top $2 \mathrm{~m}$ of the soil profile. The sand and silt content in this dome reduces down the profile. There is no translocation of clay soil in the top $2 \mathrm{~m}$ of soil. The soils are permeable to water and plant roots in the above $2 \mathrm{~m}$, and water run-off is minimal except at bear slopes above $8.53^{\circ}$. The soils here are weathered down to about $40 \mathrm{~m}$ and have high cohesion due to cementing minerals like calcium carbonate. These properties are responsible for the minimal displacement and hence the stability of such areas.

It was observed that areas that experienced landslides had high vertical displacement velocity compared to those that did not. Areas with ground cracks also experienced higher vertical displacement velocity. Areas that are at high elevation in all the transects experienced high vertical displacement velocity; however, the transects in the east had the highest rates compared to the transects in the west and the dome in the centre. In the carbonatite dome located in Bukigai, areas that had cultivated slopes and slopes above $8.53^{\circ}$ experienced higher displacement velocity. It means that vertical displacement velocity can show areas that are susceptible to landslides.

\subsubsection{InSAR-Derived Vertical Displacement Time Series}

The knowledge of the vertical ground displacement velocity alone is not sufficient to assess how unstable areas are. There is a need to extract and analyse Vertical displacement time-series for individual points for rates and magnitudes of movement. It helps to understand how displacements vary from point to point in the immediate neighbourhood. Additionally, the vertical displacement 
varies with slope and the extracted displacement time-series magnitudes were based on stability slope categories in the Bududa, these are gentle slopes $\left(0^{\circ}\right.$ $\left.9^{\circ}\right)$, medium slopes $\left(10^{\circ}-31^{\circ}\right)$ and steep slopes $\left(32^{\circ}-60^{\circ}\right)$. It was observed that gentle slopes $\left(0^{\circ}-9^{\circ}\right)$ experienced the least displacement. The medium slopes $\left(10^{\circ}-31^{\circ}\right)$ experienced higher than average displacement and steep slopes $\left(32^{\circ}-\right.$ $60^{\circ}$ ) very high displacement and many landslides as shown in Figure 5.

The vertical displacement in the low lying, middle and upper slopes in Bududa transect with gentle, medium and steep slopes at P1, P2 and P3 with slopes of 5, 26 and 45 degrees, respectively, experienced displacement velocity of $0.9,3.09$ and $5.23 \mathrm{~cm} / \mathrm{yr}$. Additionally, the displacement magnitudes at these points were 2, 6 and $9 \mathrm{~cm}$ in the two years of observation. The gentle and medium slopes were observed to experience low displacement velocities, and magnitudes see Figure 6(b) and Figure 6(c). The gentle slopes did not have cracks as evidence of displacement, but the medium slopes had cracks of smaller separation than those in steep slopes. The low-lying areas contained Fluvic Cambisols soils with more sand textured soil than clay layers and stagnation was not common. Low rainfall is received in these areas, and together with the soil type, limited displacement is observed. The middle areas with medium slopes, see Figure 6(b), with Rhodic Nitisol soils, experienced higher displacement compared to the low-lying areas but less than that at the upper steep sloped points. At the steep upper slopes, see Figure 6(a), vertical displacement velocity and magnitude were high, evidenced by cracks of larger separation and landslide scars. The soils at the steep slopes were Rhodic Acrisols, which had sand, silt, gravel, and clay layers with evidence of lines of weakness in the deeper soils. This soil stagnation, together with steep slopes, caused fast-displacement at these points. These soils had a sequence of buried soil profiles that indicated the presence of past landslide activities. The people living in the Bududa transect estimated landslides in this area to reoccur after approximately 100 years [45]. These points were observed to receive higher rainfall due to the local microclimate, which contributed to high water run-off. All the points, at gentle, medium and steep slopes experienced subsidence as is shown in Figures 6(a)-(c).

The vertical displacement in the gentle, medium and steep slopes in Bushika transect sampled at P4, P5 and P6 with slopes of 7, 28 and 50 degrees respectively, experienced displacement velocity of 2.66, 3.96 and $5.59 \mathrm{~cm} / \mathrm{yr}$ in Bushika. The displacement magnitudes at these points were 5,7 and $12 \mathrm{~cm}$, respectively. The gentle and medium slopes experienced lower displacement velocities and magnitudes but the medium slopes underwent higher displacement rates and magnitudes. The displacement velocities and magnitudes in Bushika are generally higher than those in Bududa, even if these transects generally have similar soil characteristics. The displacement can be justified by the more substantial ground cracks and landslide incidences in Bushika compared to Bududa transect. The gentle slopes here also had evidence of displacement due to higher 
P3: Slope: $45^{\circ}$

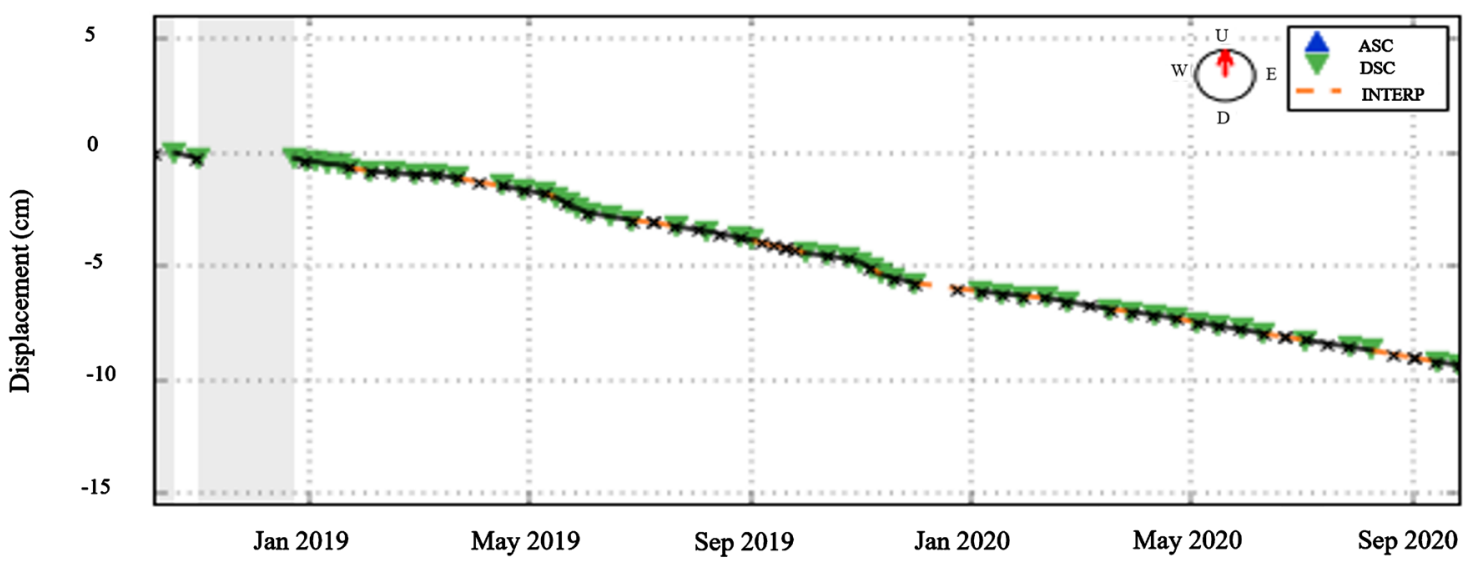

(a)

Vertical Displacement

P2: Slope: $26^{\circ}$

Rate: $3.09 \mathrm{~cm} / \mathrm{yr}$.

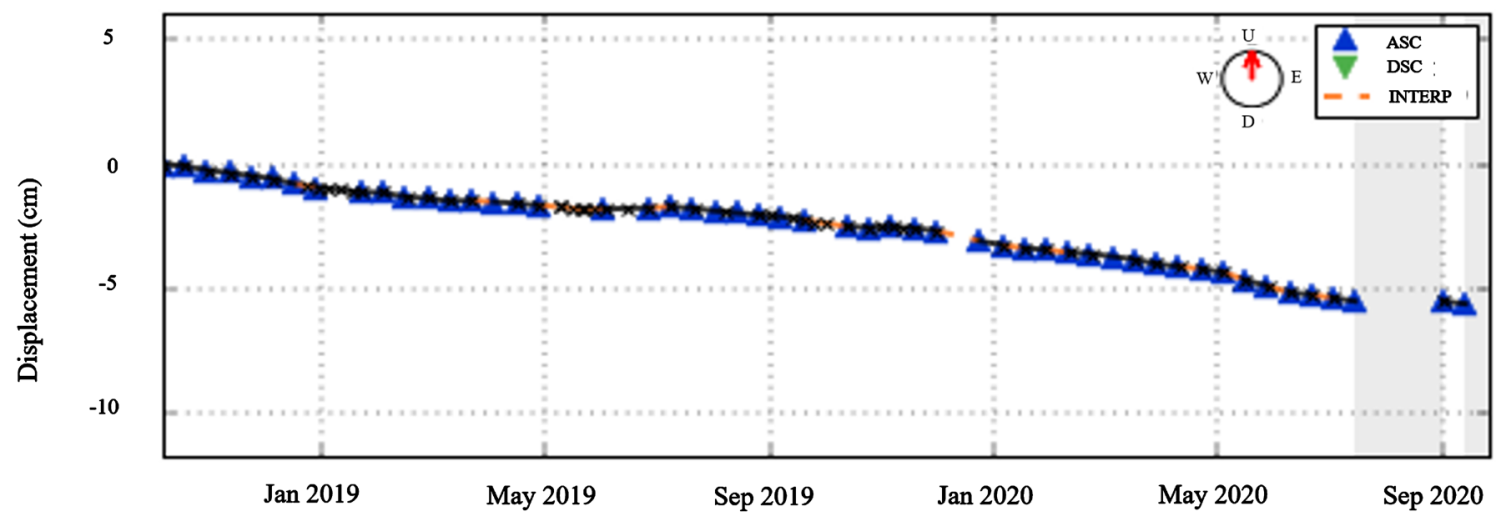

(b)

Vertical Displacement

Rate: $0.9 \mathrm{~cm} / \mathrm{yr}$.

P1: Slope: $5^{\circ}$

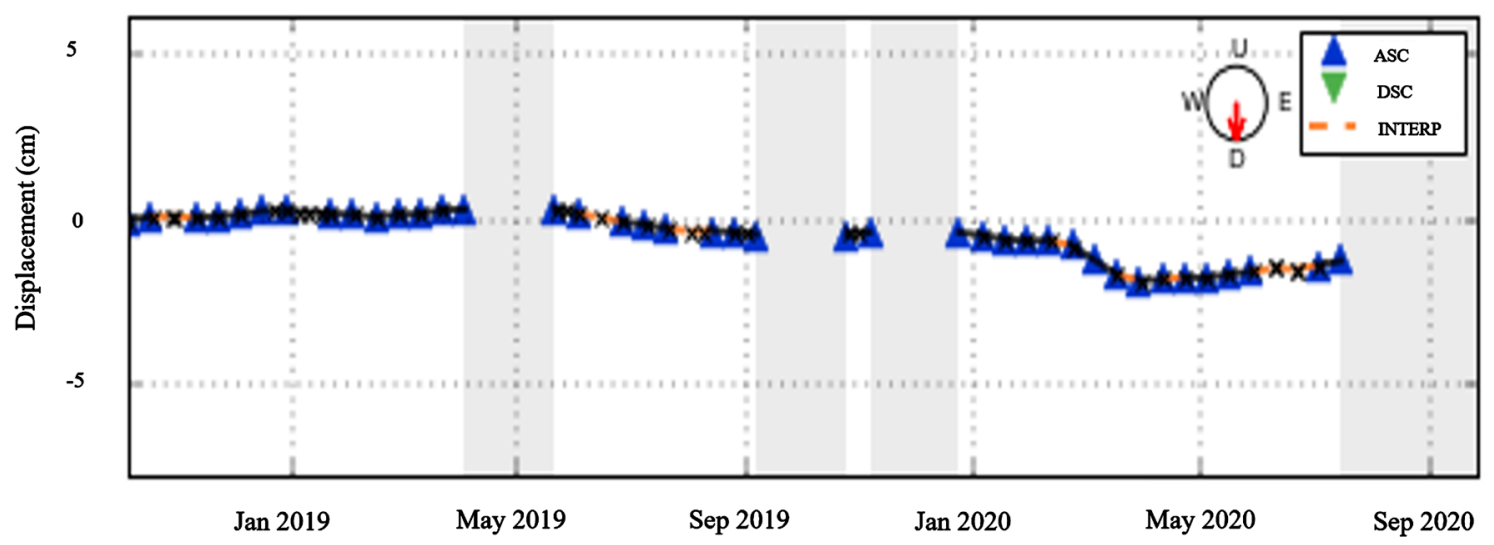

(c)

Figure 6. Time series magnitudes of vertical displacement are extracted from three points in Bududa Transect at 5, 26 and 45-degree slopes, representing gentle, medium and steep slopes samples at P1, P2 and P3. 
displacements in the low-lying areas than what was observed in the Bududa transect. The points at the gentle and medium slopes in Bushika consisted of Haplic Lixisols, which contained a higher sand content than at the steeper slopes. These, however, had slightly more clay than the areas of similar slope in Bududa and hence experienced to a degree stagnation of water as it infiltrated through the soil. The steep slopes at the upper parts of the hills consisted of Endo-Skeletic Cambisols and Rhodic Nitisols soils rich in clay. These areas have been over cultivated due to the large population. The over-cultivation has cleared the soil bare, and water run-off is very high. The saturation of water increases its weight which causes the soil to subside at steep slopes as is shown Figures 7(a)-(c). Therefore, it should be noted that generally, in Bushika, high vertical displacement magnitudes and rates in the Bushika transect are attributed to high soil horizon stratification favouring water stagnation in lower horizons, as observed by [46] [47] [48] [49] [50]. This is evidenced by many ground cracks observed in this transect and the numerous landslide incidences that have been experienced in Bushika. The slopes are at higher elevation and slope in comparison to Bududa transect and the slopes have been over cultivated due to the high population.

The vertical displacement at all points in Bushika transect is subsidence, just like in Bududa. The only difference is that the rates and magnitudes of displacement are higher in Bushika than Bududa. These transects having generally similar soil characteristics, this difference in the displacement may be attributed to the higher elevation in Bushika which has contributed to higher rainfall received. The slopes are also steeper in Bushika compared to majority of Bududa transect. The population that has settled in Bushika is also higher than that in Bududa due to the fertile soils and the reliable rainfall favouring agriculture. It should be noted that the highest points north of Bushika were located in a protected area which was covered by Mountain Elgon national part that stretched from the east. The protected area is slowly being destroyed as people want to exploit the unexhausted soils.

The vertical displacement in the gentle, medium and steep slopes sampled in the Bukigai Carbonatite dome at P7, P8 and P9 with slopes of 3, 15 and 34 degrees respectively, experienced displacement velocity of 1.7, 2.2 and $3.02 \mathrm{~cm} / \mathrm{yr}$. The displacement magnitudes at these points were 3,5 and $6 \mathrm{~cm}$, respectively. The gentle, medium and steep slopes were observed to experience low displacement velocities and magnitudes compared to other transects as is shown in Figures $8(a)-(c)$. The vertical displacement velocity and magnitude was observed to be high at the outskirts of the dome next to Bududa, Bushika, Nusu Ridge and Bukalasi transects and low in the centre of the dome were the sample points were selected. The soils are Rhodic Nitisols and are rich in clay, the clay content is more than $30 \%$ according to [46], and it varies less than $20 \%$ over above $12 \mathrm{~cm}$ in the top $2 \mathrm{~m}$ of the soil. These soils are permeable to water and plant roots in the top $2 \mathrm{~m}$, and there is little run-of erosion at the centre of the dome except on 
Vertical displacement

Rate: $5.59 \mathrm{~cm} / \mathrm{yr}$.

P6: Slope: $50^{\circ}$

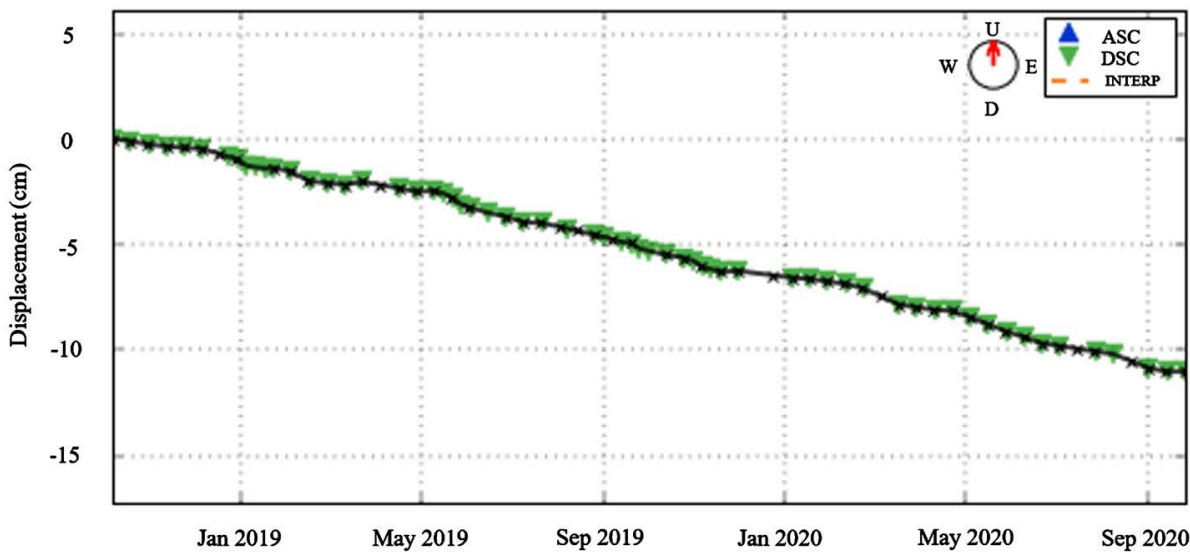

(a)

Vertical displacement

P5: Slope: $28^{\circ}$

Rate: $3.96 \mathrm{~cm} / \mathrm{yr}$.

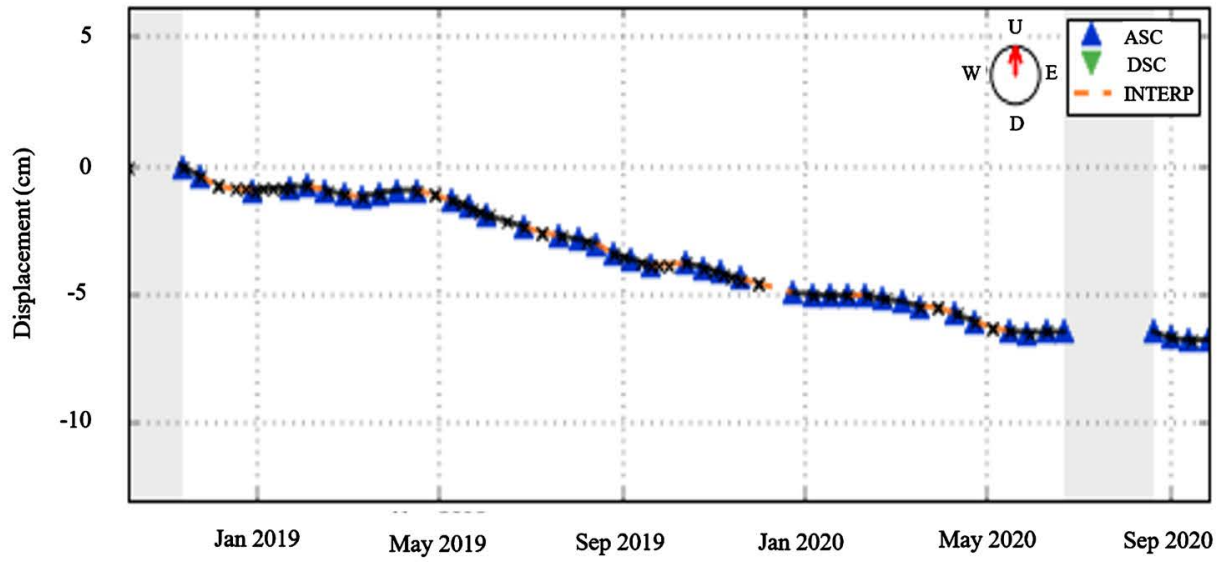

(b)

Vertical displacement

Rate: $2.66 \mathrm{~cm} / \mathrm{yr}$

P4: Slope: $7^{\circ}$

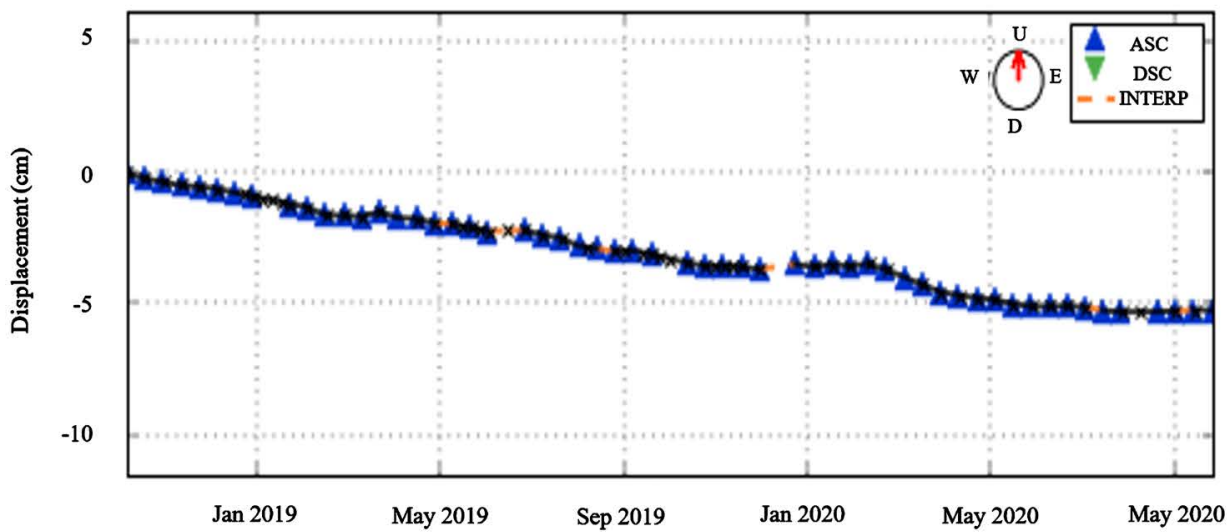

(c)

Figure 7. Vertical displacement and time-series magnitudes of vertical displacement are extracted from three points in Bushika Transect at 7, 28 and 50-degree slopes, representing gentle, medium and steep slopes samples. 
Vertical Displacement

P9: Slope:34

Rate:3.02 cm/yr.

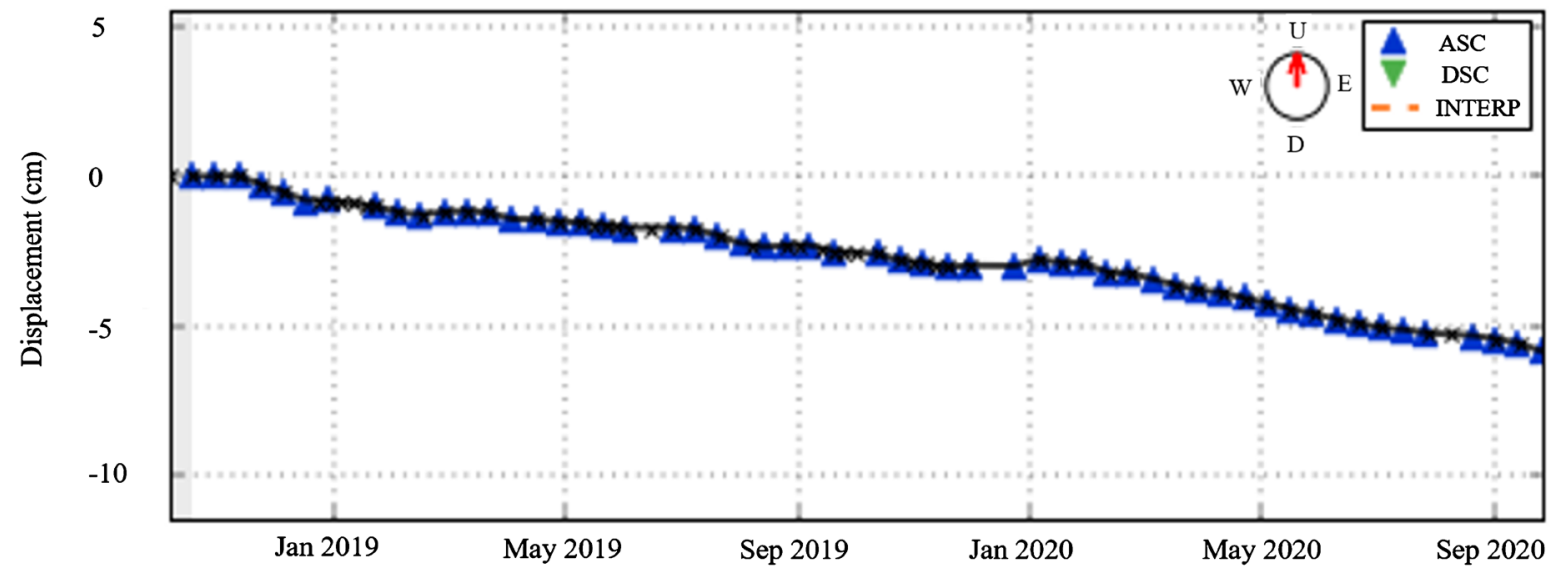

(a)

Vertical Displacement

Rate: $2.2 \mathrm{~cm} / \mathrm{yr}$.

P8: Slope: $15^{\circ}$

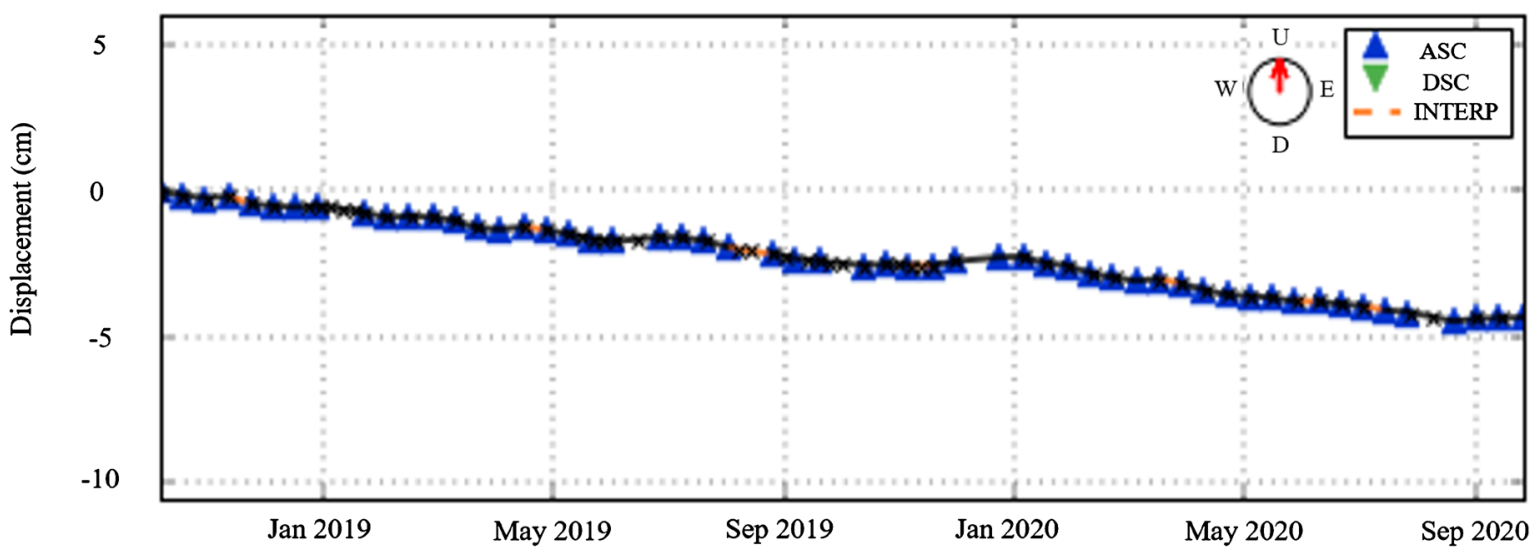

(b)

Vertical Displacement

P7: Slope: $3^{\circ}$

Rate: $1.71 \mathrm{~cm} / \mathrm{yr}$.

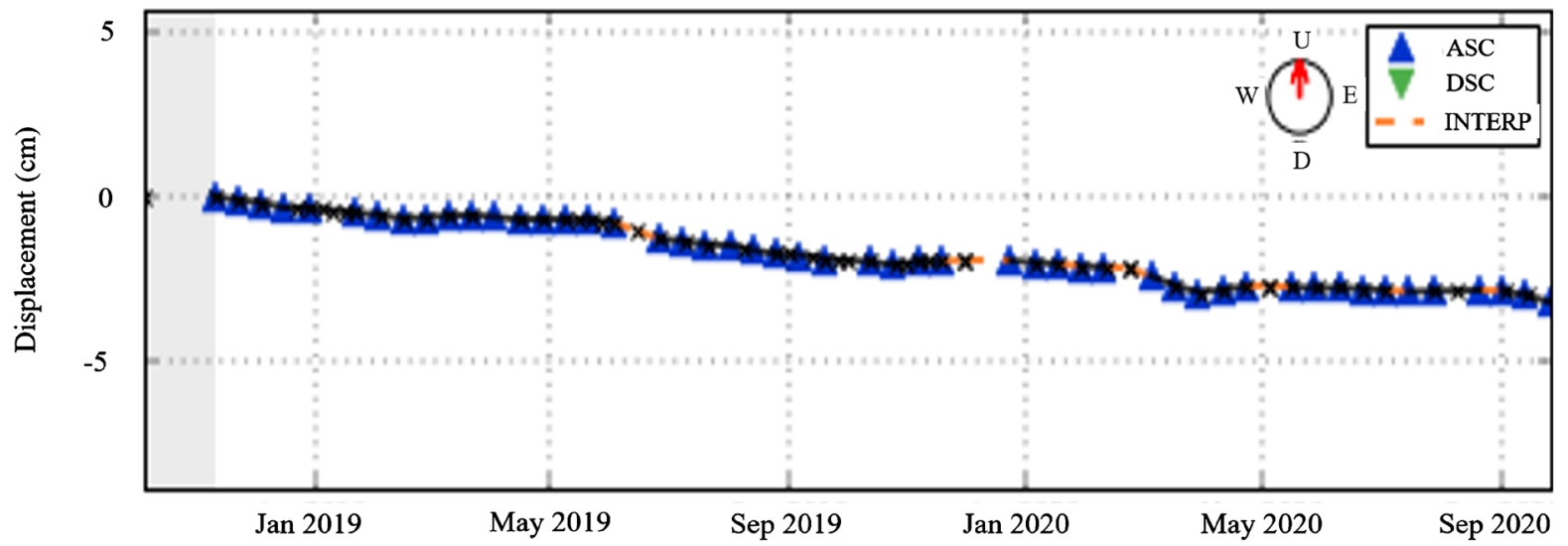

(c)

Figure 8. Vertical displacement and time-series magnitudes of vertical displacement are extracted from three points in Bukigai Carbonatite Dome at 3,15 and 34-degree slopes, representing gentle, medium and steep slopes samples P7, P8 and P9. 
unprotected slopes exceeding slopes of $8.53^{\circ}$ that were observed at the outskirts of the carbonatite dome. The Rhodic Nitisols commonly observed central to the carbonatite dome are very stable and experience very limited ground displacement, and hence landslides are not common in this area. In the research conducted by [46] soils in this transect were drilled to about 40 meters and identified were minerals such as magnetite and hematite, which are rich in iron; hence the stability of these soils results from the high cohesion that results from cementing minerals like carbonate.

In the Nusu ridge, the vertical displacement in the gentle, medium and steep slopes sampled at P12, P10 and P11 with slopes of 4, 25 and 55 degrees, respectively, experienced displacement velocity of $0.98,4.11$ and $6.42 \mathrm{~cm} / \mathrm{yr}$. The displacement magnitudes at these points were 2,8 and $9 \mathrm{~cm}$, respectively. The gentle slope sampled at the flat top peak of Mountain Elgon, as seen at P12 in Figure 5 experienced low displacement velocity and magnitude. The medium middle and steep upper slopes in Nusu ridge experienced very high vertical displacement, as shown in Figure 9(a) and Figure 9(b). The vertical displacement magnitudes observed were also subsidence as seen elsewhere in Bududa District. High vertical displacement velocity and magnitudes were observed west of the Ridge, where communities' occupation has destroyed the vegetation cover. The western part of the Ridge has experienced the highest number of landslides in Bududa District similar to Bukalasi transect; these landslides are shallow and translational compared to the deep rotational landslides experienced in Bududa and Bushika transects [46] [47] [49] [50]. The areas west of the Ridge also experience high vertical ground displacement due to other factors, including terraces, steep slopes, cultivation and concavity of the slopes [51] [52] [53] [54] [55]. Low velocity and magnitudes were observed in the east next to and at the peak of the mountain Elgon with minimal slope, a thin layer of topsoil and no human habitation. This is attributed to less human activity in such areas hence minimal movement recorded, and no landslides reported. The areas occupied by thick vegetation of traditional trees in Mountain Elgon National park also did not experience high displacement as the similar areas that had been cleared for habitation and agriculture by communities.

In Bukalasi transect, the vertical displacement in the gentle, middle and upper sampled points at P13, P14 and P15 located in the gentle, medium and steep slopes of 9,19 and 60 degrees experienced displacement velocity of $0.26,4.24$ and $5.96 \mathrm{~cm} / \mathrm{yr}$. The displacement magnitudes at these points were also 2, 8 and $12 \mathrm{~cm}$, respectively. The gentle slope sampled at a low-lying point in Bukalasi transect experienced low displacement velocity and magnitude. The middle medium and steep upper slopes in Bukalasi experienced very high vertical displacement like in Nusu Ridge, as is shown in Figures 10(a)-(c).

The points positioned lower in the slopes all experienced low vertical displacement velocity and magnitudes. It was the case in all the other transects that were analysed throughout the District. Soils in Bukalasi transect in the lower 
P11: Slope: $55^{\circ}$

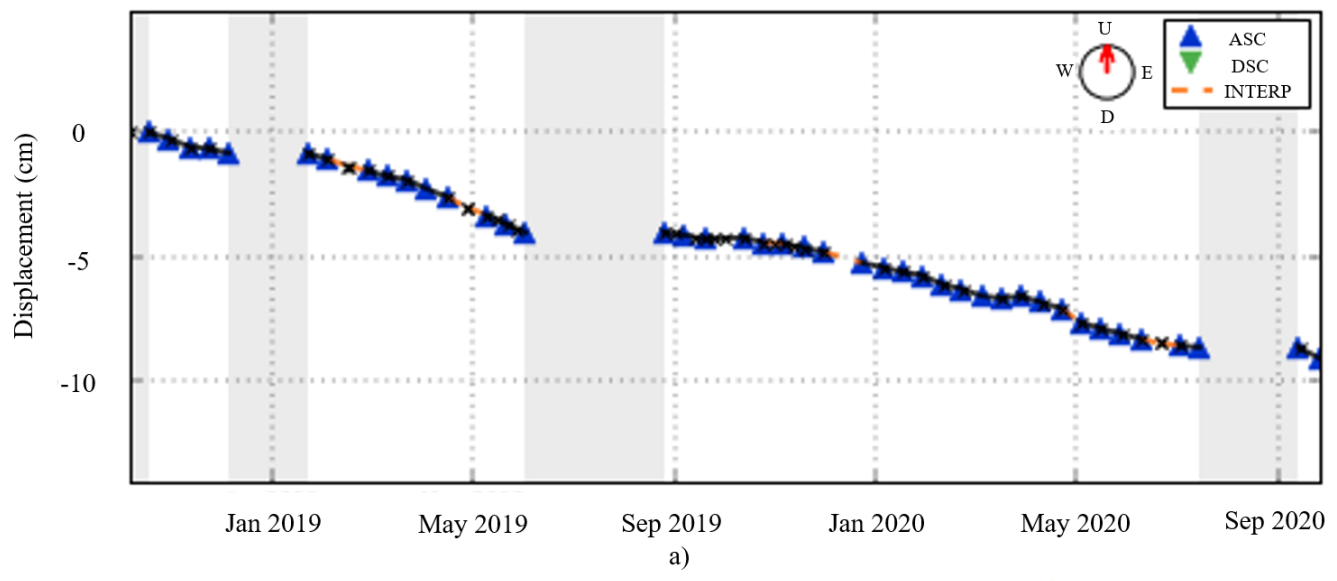

Vertical Displacement

Rate: $4.11 \mathrm{~cm} / \mathrm{yr}$.

P10: Slope: $25^{0}$

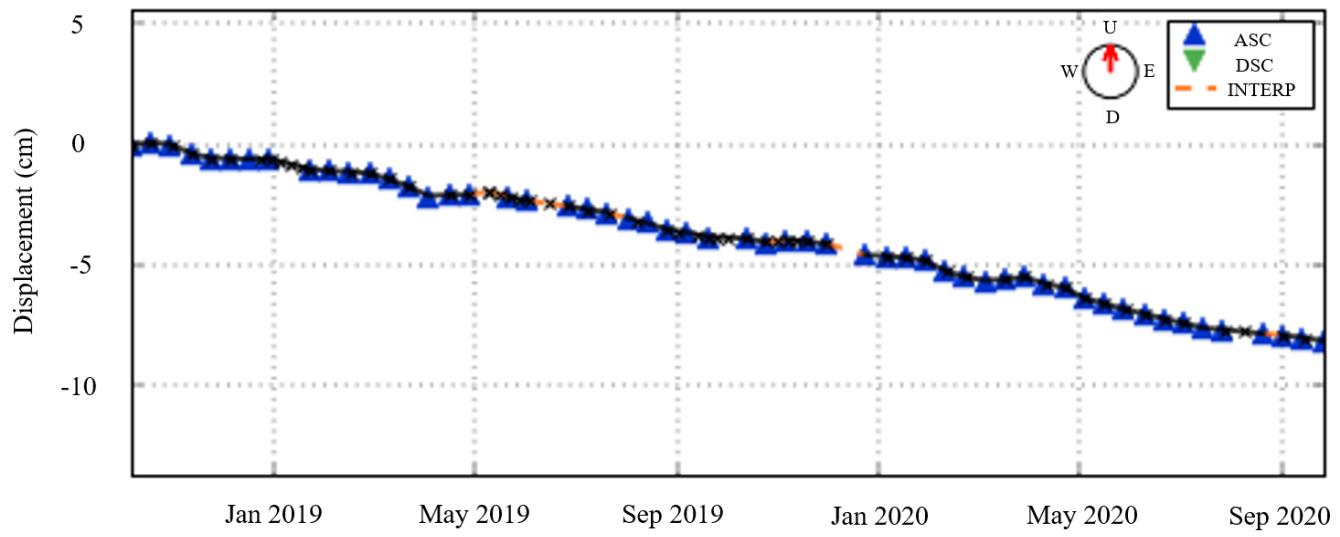

b)

P12: Slope: $4^{0}$

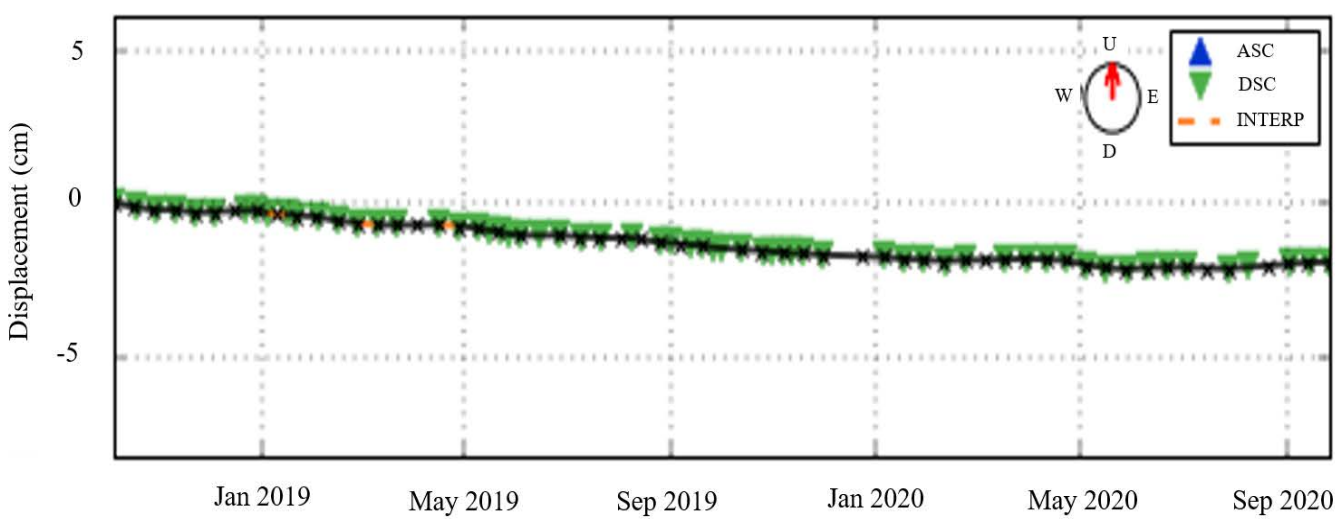

c)

Figure 9. Vertical displacement and time-series magnitudes of vertical displacement are extracted from three points in Nusu Ridge at 4, 34 and 55-degree slopes, representing gentle, medium and steep slopes samples P10, P11 and P12. 
Vertical Displacement

Rate: $5.96 \mathrm{~cm} / \mathrm{yr}$.

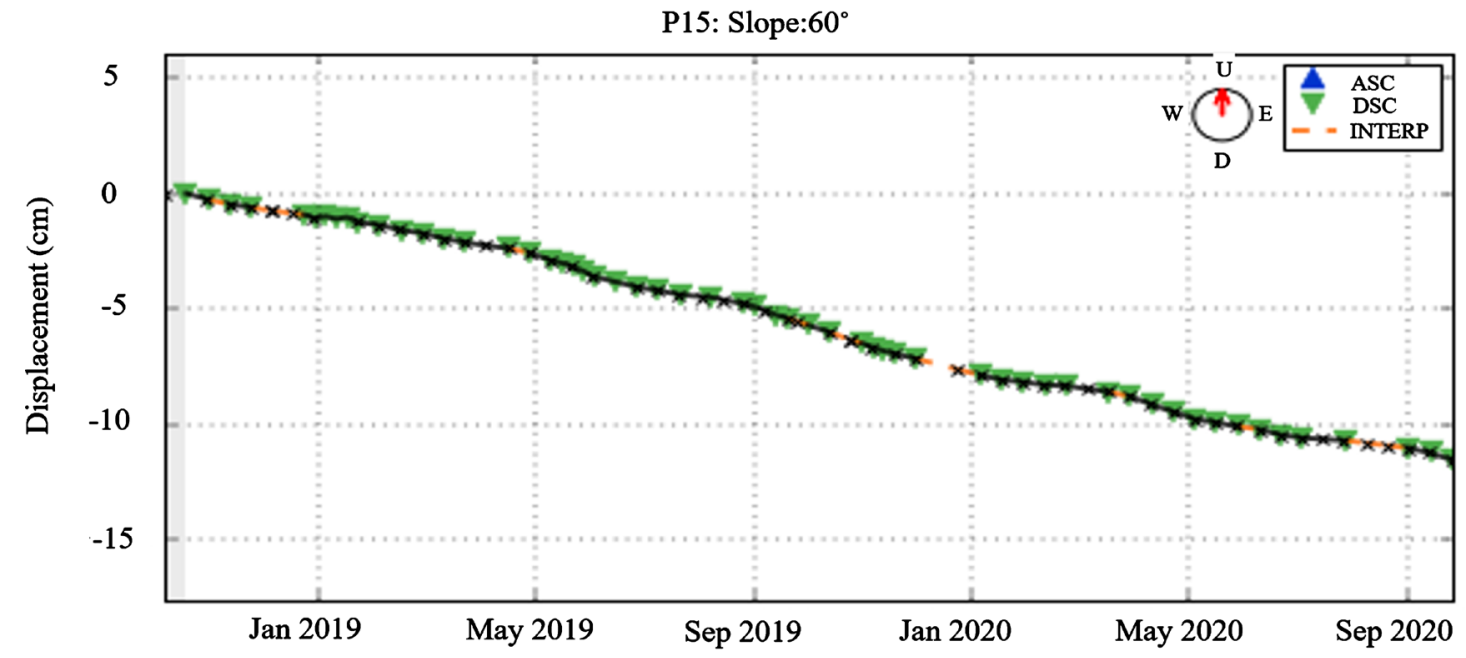

(a)

Vertical Displacement

Rate: 4.24 cm/yr.

P14: Slope:19

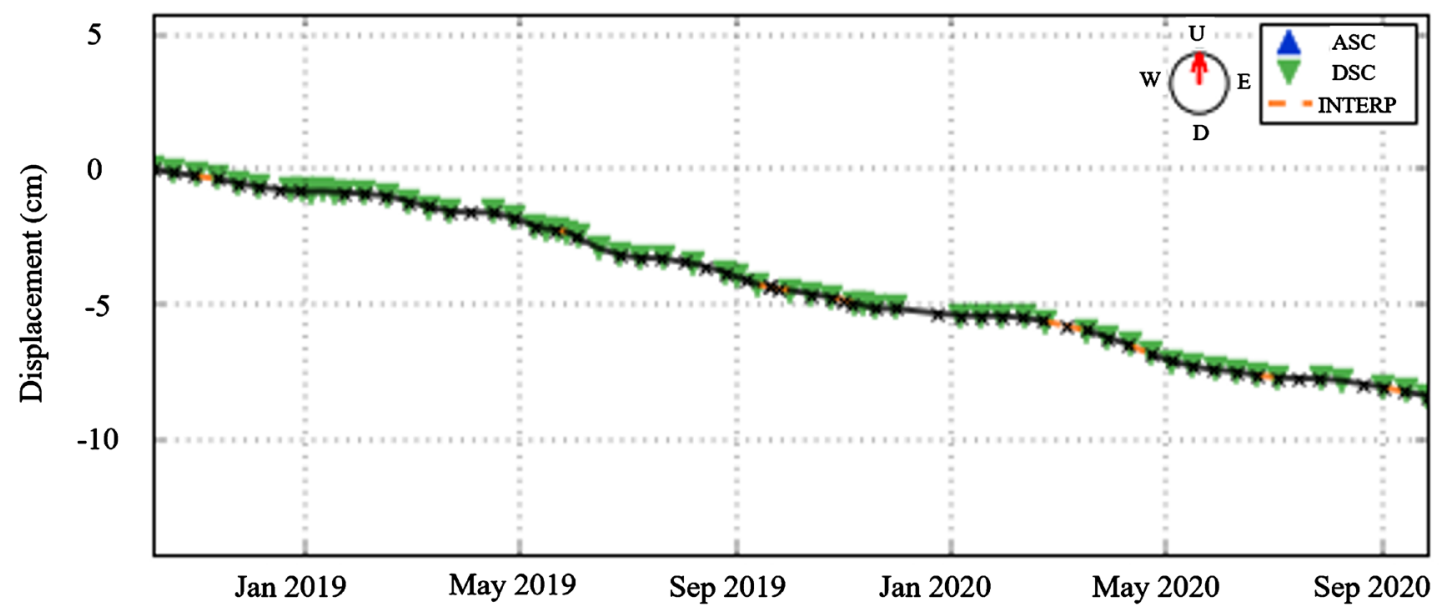

(b)

Vertical Displacement

Rate: $0.26 \mathrm{~cm} / \mathrm{yr}$.

P13: Slope:9

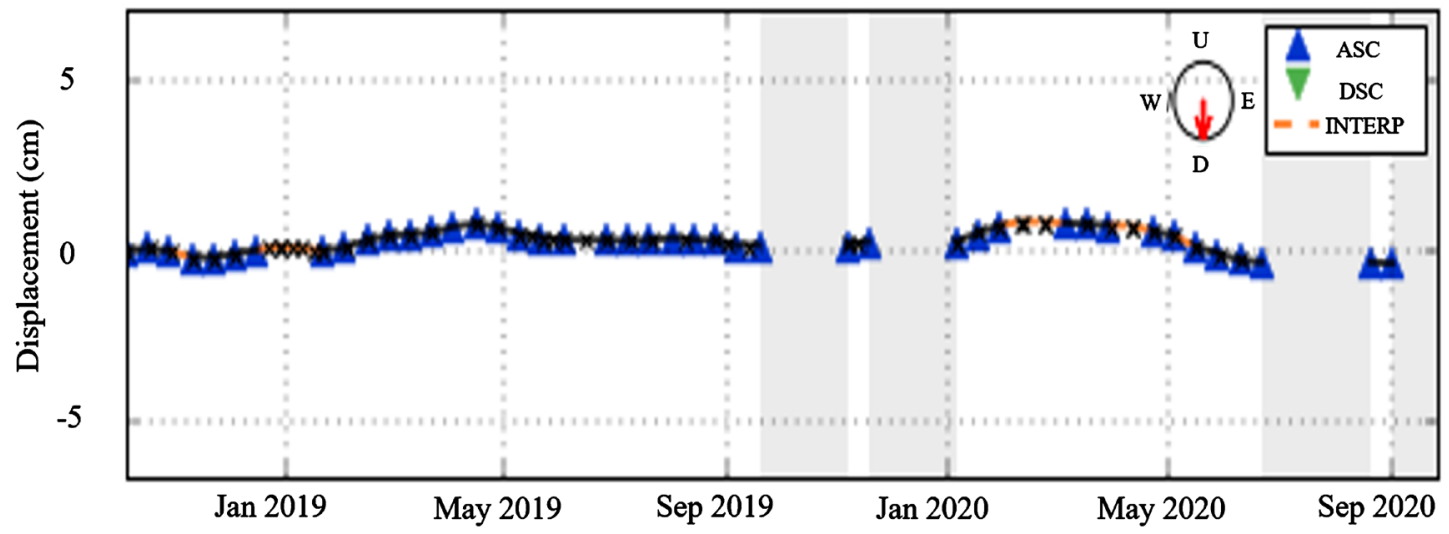

(c)

Figure 10. Vertical displacement and time-series magnitudes of vertical displacement are extracted from three points in Bukalasi Transect at 9, 19, and 60-degree slopes, representing gentle, edium and steep slopes samples P13, P14 and P15. 
points were Haplic Ferralsol, while in the middle and upper parts were Haplic Acrisols and Rhodic Lixisols, generally with high clay content. These points, similar to the majority of points in Bududa had low drainage, saturation, field capacity, and bulk density. It was observed that the soils sampled at all the transects except those at the Bukigai Carbonatite dome especially those at the upper and steep slopes and afew middle and medium slopes like in Bushika, Nusu ridge and Bukalai transects, the low drainage rates, saturation and field capacity caused high surface run-off when it rained. The low bulk density caused stagnation of water at clay horizons and given steep slopes at some points displacement was very high. The fast water flow down the soil profiles meets higher soil clay content, causing water to stagnate, and under steeper slopes, displacement occurs. It was exacerbated by the slopes' cultivation and the high rainfall that is received in the transect. Most upland soils in the steep slopes and pediments are deep and porous in the top $1 \mathrm{~m}$ of clay loams or clays. They have minimal or no laterite and do not exhibit horizon differentiation in the top $20-25 \mathrm{~cm}$, only changes in how firm the soil is. A factor that has been seen to be responsible for vertical displacement.

Additionally, many streams radiate from almost all directions; these have been responsible for landslides that result from flash floods. However, the development of these kinds of landslides cannot be done by solely monitoring ground displacement. Other measures like streamflow and water levels should be monitored.

\subsubsection{InSAR-Derived and GPS Vertical Displacement Time Series}

The InSAR derived vertical displacements were compared with GPS displacements at P3, P6 and P11 in Bududa, Bushika and Bulucheke. These points had experienced landslides in the past, they had GPS monuments installed and vertical displacement determined through the PS-InSAR technique. This was done to determine how comparable and reliable vertical displacements determined by PS-InSAR are.

GPS data has high reliability in the $\mathrm{x}, \mathrm{y}$ and $\mathrm{z}$ directions but has a low spatial resolution. On the other hand, PS-InSAR has a high spatial, temporal resolution. Still, measurements are in the Line of Sight (LOS), necessitating ascending and descending satellite tracks to estimate vertical displacement. In this study, the PS-InSAR LOS displacement is projected to the vertical direction using Equation (4). This displacement is compared with vertical displacement derived from campaign GPS measurements at these 3 points.

According to the Root Mean Square Error (RMSE) error between PS-InSAR and GPS, there is a relative agreement between the vertical displacement estimated by the two techniques, as is shown in Figures 11(a)-(c). This will help combat the difficulty of having GPS stations installed everywhere, a significant weakness of monitoring ground displacement compared to InSAR, which has high spatial resolution and is now reliable in estimating vertical displacement as determined in this study. Furthermore, there are fluctuations in GPS measurements 


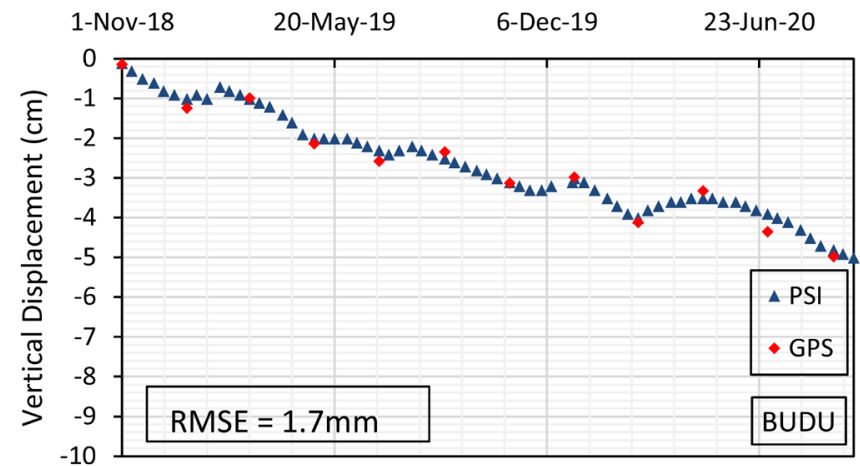

(a)

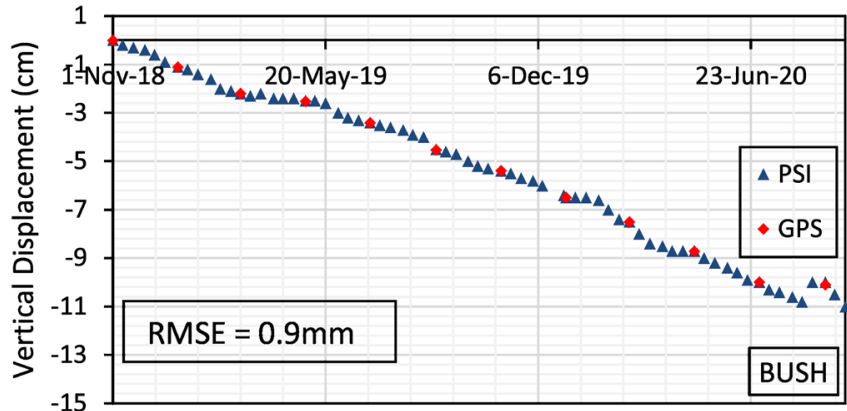

(b)

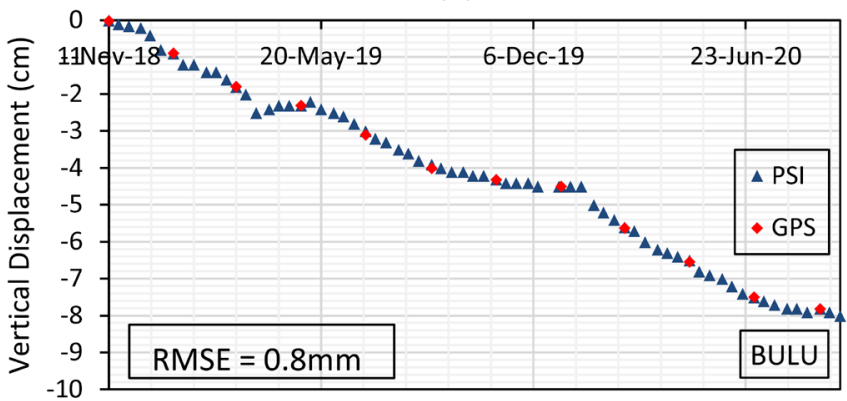

(c)

Figure 11. Comparison between PS-InSAR (PSI) and GPS derived Vertical displacement at BUD-P3 (a), BUSH-P6 (b) and BULU-P11 (c) stations found in Bududa, Bushika and Nusu Ridge transects.

due to seasonal effects and instrument set up error, making PS-InSAR advantageous.

Even if InSAR has some advantages over GPS, like high spatial coverage, GPS stations will still be essential in displacement measurement and cannot be substituted by InSAR technology. InSAR still provides displacement in two directions. We assume a zero north-south deformation, which is true in many situations compared to GPS that estimates displacement with sufficient reliability in three directions. GPS data is still part of many applications where InSAR has been used to derive ground velocities. Furthermore, GPS data is still used in many circumstances to estimate ground strain in disaster-stricken areas. Yet, InSAR has not been incorporated in strain analysis due to the limitation of not reliably determining displacement in all directions, which will not be the case in the future according to current research trends in InSAR technology. 
3.1.4. InSAR-Derived Vertical Displacement, Rainfall and Soil Properties InSAR derived vertical displacement was further correlated with rainfall received at the three sampled points. It was observed that the correlation between vertical ground displacement and rainfall in Bududa was strong, as is shown in Figures 12(a)-(c), which was $\mathrm{R}^{2}$ of $0.9572,0.9844$ and 0.9821 in BUDU, BUSH and BULU. It implies that when rainfall is high, the vertical ground displacement will also be high. The incremental movement of soil is affected by driving and resisting forces affected by absorbed and drained water at multiple scales and rates. When rainfall penetrates the bedrock, rock slabs are split or pulverised through mechanical weathering; hence ground displacement occurs. Dense vegetation

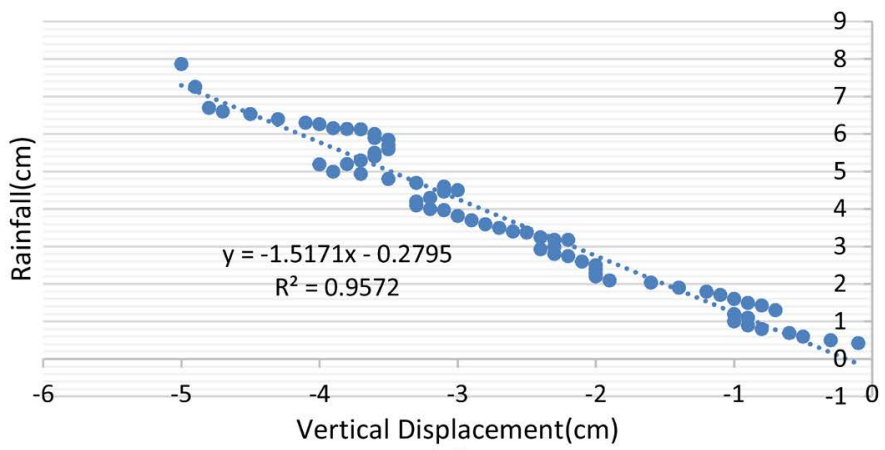

(a)

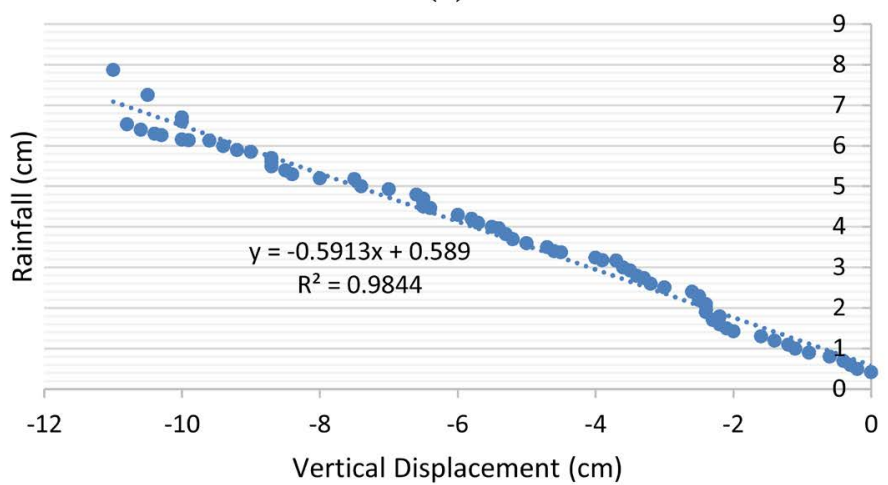

(b)

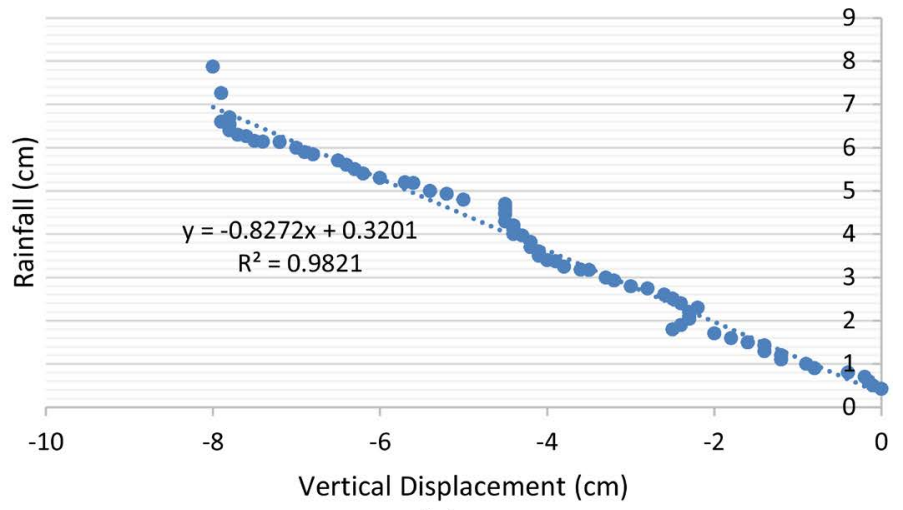

(c)

Figure 12. The correlation between InSAR derived vertical displacement and rainfall received at BUDU (a), BUSH (b), and BULU (c) stations in Bududa, Bushika, and Nusu Ridge transects. 


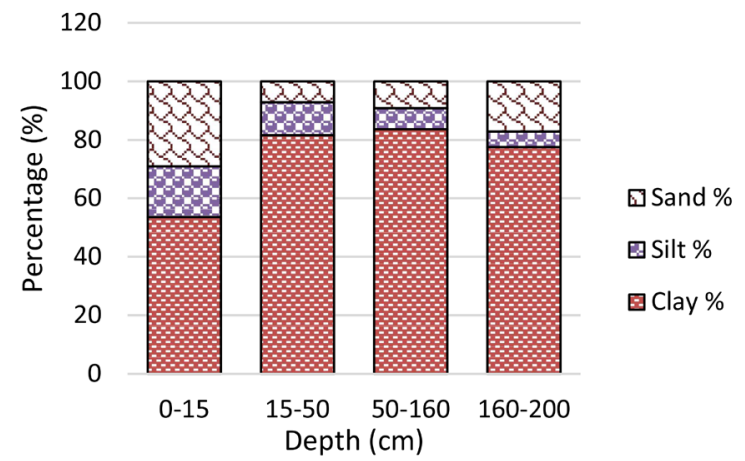

(a)

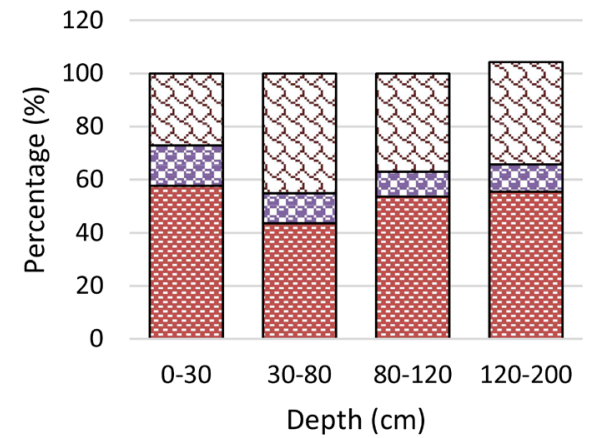

\section{Sand \% \\ 曰Silt \% \\ 조 Clay \%}

(b)

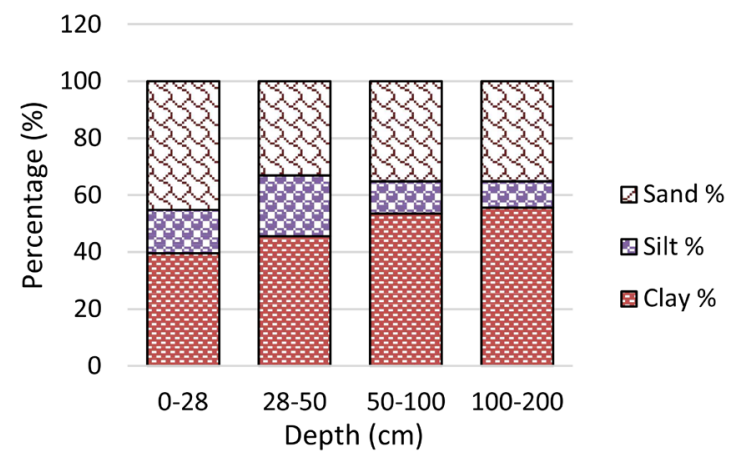

(c)

Figure 13. The soil text classes of clay, silt and sand at different depths till $200 \mathrm{~cm}$ at Bududa (BUDU) (a), Bushika (BUSH) (b) and Bulucheke (BULU) in Nusu Ridge (c).

cover may restrict rainfall from reaching the soil, and tall vegetation keeps the soil dry through the causation of high levels of evapotranspiration. Soil, rock and rainfall have a complex interaction that influences the threshold between stable slopes and those moving.

Ground displacement occurs when driving forces exceed resisting forces. The most common resisting forces are shear forces. The shear forces influence substrates that adjoin slip planes. Soils tend to have higher shear strength than rocks due to soil's cohesive strength from soil's adhesive properties. An increase in the weight of the soil on the slope increases the driving forces. An increase in weight can be due to prolonged rains and saturation of soils on steep slopes. Water from rainfall saturates the soil, adds weight and pore pressure hence reducing resistance or suction through the separation of soil particles. Rainfall, however, 
contributes to slow displacement but more frequent and spatially distributed than earthquakes and volcanoes, which cause larger displacement but less frequent. Heavy rains further cause displacement by temporally raising the water table to a shallow depth, and the rising water table results from surface infiltration into unsaturated soils than deep percolation. The extreme case will be when the water rises until it reaches the surface, implying that it is entirely saturated. The saturation of soil increases the pore pressure significantly. Soil saturation forces the soil particles apart, reducing inter soil particle friction, cohesion, shear strength and resisting forces. Given the low drainage rates, field capacity and saturation of the sampled soils as observed in Figures 14(a)-(c) it is the reason the sampled points exhibited high displacement magnitudes.

The soil texture at the sampled points contained clay above $30 \%$, as is shown in Figures 13(a)-(c). The high clay content was observed up to $200 \mathrm{~cm}$ depths but with layering, especially at BUSH and BULU compared to BUDU. The points where clay layering occurred acted as stagnation points. Water that managed to infiltrate the upper layers was restricted from quickly moving through these clay layers, causing an increase in the soil's weight at such points. The weight of water above the clay layer considering the steep slopes caused high displacement velocity and magnitudes at such points.

The soils experience meagre drainage rates due to the high clay content shown in Figure 14(a). The sampled points at Bulucheke (BULU), Bushika (BUSH) and Bududa (BUDU) had drainage rates of $0.201,0.169$ and $0.19 \mathrm{~cm} / \mathrm{hr}$. It is observed that with this low drainage rate Bududa experienced high rainwater run-off, which caused flash floods and mudflows. Bushika with these least drainage rates experienced high stagnation at clay layering hence displacement, which is evidenced

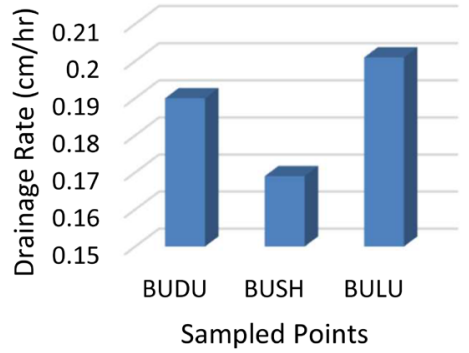

(a)

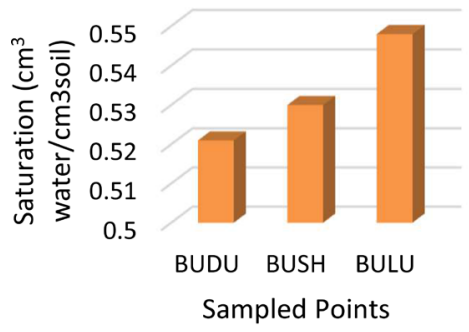

(c)

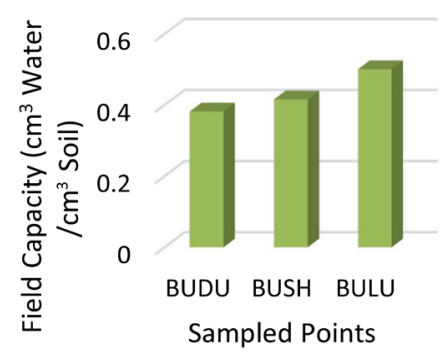

(b)

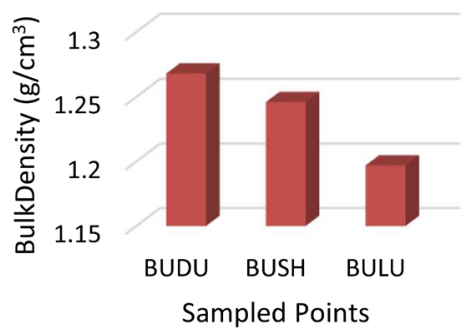

(d)

Figure 14. The drainage rate, field capacity, saturation and bulky density of sample points at Bududa (BUDU) (a), Bushika (BUSH) (b) and Bulucheke (BULU) in Nusu ridge transect (c). 
with many cracks in this transect.

Apart from the sampled points having low drainage rates. They additionally had high field capacity. This means the amount of water or mositure that was held in the soil after excess water drains away, and the rate of downward movement decreases was low. The observed values of the field capacity at the sampled points were $0.382,0.416$ and $0.501 \mathrm{~cm}^{3}$ water $/ \mathrm{cm}^{3}$ soil in BUDU, BUSH, and BULU. The soils had a high field capacity because they have a high clay content; therefore, they retained more water and longer. It contributed to the high displacement rates and magnitudes in the sampled points. The sampled points in Bududa additionally had saturation values of $0.521,0.53$ and $0.548 \mathrm{~cm}^{3}$ water $/ \mathrm{cm}^{3}$ soil in BUDU, BUSH and BULU. The soils easily saturated with water due to the high clay content of the soils. The soils additionally had how bulk density. The bulk density values were $1.268,1.246$ and $1.197 \mathrm{~g} / \mathrm{cm}^{3}$ in BUDU, BUSH and BULU. It showed that the soils contained less sand, which caused these soils to drains less and held more water.

\subsection{Discussion}

Ground vertical displacement velocity and magnitude were determined using the PS-InSAR. The displacement was compared with GPS to validate its reliability and further extracted for different slope ranges. That is $0^{\circ}$ to $9^{\circ}, 10^{\circ}$ to $31^{\circ}$ and $32^{\circ}$ to $62^{\circ}$, representing low-lying, middle and upper parts. This was done to determine the relationship between ground displacement and slope. The displacement was further compared with rainfall to determine the influence of rain on ground displacement. Finally, the soils texture, drainage rate, field capacity, saturation and bulk density at sampled points were determined and compared with displacement at these points.

Vertical displacement velocity in Mountain Elgon region was observed to rise to $20 \mathrm{~cm} / \mathrm{yr}$; however, in Bududa, it only reached $6 \mathrm{~cm} / \mathrm{yr}$. This vertical displacement velocity is however, considered high when compared with other research on ground displacement in landslide susceptible areas [17] [22] [27]. Sites which experienced landslides were observed to experience the highest vertical displacement velocities and magnitudes than other places. These areas also had wider cracks in the ground and buildings that indicated the existence of ground displacement. Vertical displacement magnitudes reached $13 \mathrm{~cm}$ in the two years of observation, and the displacement was majorly subsidence. The maximum vertical displacement velocity and magnitude were higher in the east of the District than the west. Additionally, the vertical displacement velocity and magnitude were low at the centre of the carbonitate dome but high at the dome's steep-sloped ring around the dome. Nusu ridge, Bukalasi and Bushika transect experienced higher vertical displacement velocity and magnitudes than the Bududa transect and the Bukigai carbonatite dome.

The PS-InSAR results were comparable to GPS as observed from the RMSE. It means that InSAR can be used as a direct replacement for GPS when all the nec- 
essary factors are in place. These include a sufficient number of SAR imagery in ascending and descending modes with different geometries, corner cube reflectors to enhance the backscatter and SAR imagery obtained from the longer wavelength. The availability of a sufficient number of SAR imagery in ascending and descending modes with significantly different geometries will enable the reliable extraction of displacement in three dimensions. It is important if InSAR is to replace GPS to reliably estimate displacement in all three dimensions.

Vertical displacement was highest at slope ranges between $32^{\circ}$ and $60^{\circ}$ followed by slopes between $10^{\circ}$ and $31^{\circ}$ and most minor between $0^{\circ}$ and $9^{\circ}$. It showed that a change in slope largely drove displacement. The vertical displacement was also highly correlated with rainfall, which showed that the main triggering factor for displacement was rainfall. The soils were observed to have a very high clay content than silt and sand, contributing to low drainage rate, field capacity, saturation, and bulk density. These physical properties of the soil contributed high displacement rates and magnitudes in Bududa.

The study results meant that uplands are unstable compared to low lying areas, making such areas susceptible to landslides. Additionally, steep-sloped areas above $8.53^{\circ}$ as located in Nusu ridge, Bukalasi, Bushika and parts of Bududa and Bukigai Carbinoite dome are unstable and susceptible catastrophic landslides. It further showed that displacement is a function of elevation as east of the district high elevation points experienced substantial vertical displacement velocity and magnitudes. Slope, soil characteristics and vegetation cover were observed to control vertical displacement rates and magnitudes in Bududa. This is because low slope places at high altitude like at the peak experienced downward movement. It is also observed that when PS-InSAR results are projected into the vertical direction, the displacement estimated is reliable as it was determined when compared with GPS vertical displacement. This further means that PS-InSAR can be used in place of GPS if vertical displacement is to be estimated. It, however, should be done when the PS-InSAR processing is reliably done with all the error sources reliably quantified and eliminated.

It was observed that PS-InSAR estimates displacement reliable in the LOS and the vertical direction. It is the case due to the north-south orbiting of the SAR satellites. Vertical displacement velocity and magnitudes are only possible with a sufficient number of ascending and descending SAR satellites with tracks of significantly different geometries. It was further observed that even in dense vegetation, the few estimated PSs are reliable for displacement estimation. These PSs are substantially more in number compared to installed GPS stations. PS-InSAR should not be used independently but in conjunction with GPS for a reliable estimate of ground displacement. The use of longer wavelength SAR images, such as $\mathrm{L}$ or $\mathrm{P}$ bands, will increase the vegetation's penetration. The comparison of continuous GPS stations would quantify the RMSE between PS-InSAR and GPS to assess PS-InSAR reliability better. Finally, the incorporation of corner cube reflectors would reduce the temporal decorrelation and increase the stable pixels. 
It would further improve the PS-InSAR results and the comparison of displacement at PS-InSAR and GPS points.

\section{Conclusions and Recommendations}

The Mountain Elgon region experienced high vertical displacement velocity reaching $20 \mathrm{~cm} / \mathrm{yr}$. Still, this high displacement velocity was outside the study area of Bududa, which experienced vertical displacement velocity reaching 6 $\mathrm{cm} / \mathrm{yr}$. The Vertical displacement velocity in Bududa reaching $6 \mathrm{~cm} / \mathrm{yr}$ and magnitudes of $13 \mathrm{~cm}$ in two years shows that the area is unstable. The ground displacement estimated by PS-InSAR was comparable with that from GPS, which implied that InSAR could provide reliable displacement estimates of unstable areas. Bududa had high displacement magnitudes and velocity, evidenced by developed cracks and landslide scars. The points that were downslope and had slopes between $0^{\circ}$ and $9^{\circ}$ experienced low displacement velocity and magnitudes compared to the points in the upper slopes $32^{\circ}$ to $60^{\circ}$.

Additionally, the points at the middle slopes $10^{\circ}$ to $31^{\circ}$ generally had higher displacement than normal. The Bushika, Nusu ridge and Bukalasi Transects experienced the highest displacement velocity and magnitude. The high displacement was due to horizon stratification and water stagnation at the lower horizons. Nusu Ridge and Bukalasi transect experienced higher displacement velocity except at the peak of Mountain Elgon. The higher displacement at the other transects was due to increased population, over-cultivation, terracing and steep concave slopes. Areas in Bududa transect and Bukigai carbonatite transect that did not experience high displacement were located at the lower slopes. They had soils permeable to water and plant roots experiencing little run-off erosion. The soils in the Bukigai carbonatite dome that experienced low displacement also had soils weathered to depths reaching $40 \mathrm{~m}$ derived from magnetite and hematite minerals rich in iron. These were stable due to the calcium carbonate cementing minerals.

Ground displacement in Bududa was highly correlated with rainfall. It implied that ground displacement in Bududa is majorly triggered by precipitation. It is due to the high rainfall amounts that are received in Bududa. The high rainfall amounts given the soil types, texture and slopes acted as an accelerator of ground displacement. The soils in Bududa had high clay content above $30 \%$ a condition that favours land displacement. It was also observed that soil type did not have a significant impact on ground displacement as soil texture. Furthermore, soils in these transects had low drainage rates, field capacity, saturation and bulk density that caused water to flow less through the soil profiles, causing stagnation when they came into contact with higher clay layers.

The PS-InSAR technique only estimates displacement of slow-moving displacements over points where PSs have been calculated. Estimating PSs over vegetated points poses challenges to using the PS-InSAR technique, as few PSs are estimated. The introduction of artificial reflectors for example corner cube 
reflectors could be considered. In this study, PSs estimated in light vegetated areas normally occupied by the communities at risk are useful. These are areas that are most affected by displacement due to exposed ground slopes. Vertical estimation of displacement using PS-InSAR is only reliable with over 20 ascending and descending used.

\section{Acknowledgements}

I would like to extend my appreciation to the European Space Agency (ESA), through whose data hub it was possible to access the Satellite imagery used in this study. Furthermore, I would like to thank DAAD who funded this research and Makerere University that provided the satellite imagery processing facilities.

\section{Conflicts of Interest}

The authors declare no conflicts of interest regarding the publication of this paper.

\section{References}

[1] Cruden, D.M. and Varnes, D.J. (1996) Landslides: Investigation and Mitigation. Chapter 3-Landslide Types and Processes. Special Report, 247.

[2] Delacourt, C., Allemand, P., Berthier, E., Raucoules, D., Casson, B., Grandjean, P., et al. (2007) Remote-Sensing Techniques for Analysing Landslide Kinematics: A Review. Bulletin de la Société Géologique de France, 178, 89-100. https://doi.org/10.2113/gssgfbull.178.2.89

[3] Van Westen, C.J., Van Asch, T.W. and Soeters, R. (2006) Landslide Hazard and Risk Zonation-Why Is It Still So Difficult? Bulletin of Engineering Geology and the Environment, 65, 167-184. https://doi.org/10.1007/s10064-005-0023-0

[4] Van Den Eeckhaut, M. and Hervás, J. (2012) Landslide Inventories in Europe and Policy Recommendations for Their Interoperability and Harmonisation. In: Margottini, C., Canuti, P. and Sassa, K., Eds., Landslide Science and Practice, Springer, Berlin, Heidelberg, 35-42. https://doi.org/10.1007/978-3-642-31325-7_4

[5] Cigna, F., Bianchini, S. and Casagli, N. (2013) How to Assess Landslide Activity and Intensity with Persistent Scatterer Interferometry (PSI): The PSI-Based Matrix Approach. Landslides, 10, 267-283. https://doi.org/10.1007/s10346-012-0335-7

[6] Vietmeier, J., Wagner, W. and Dikau, R. (1999) Monitoring Moderate Slope Movements (Landslides) in the Southern French Alps Using Differential SAR Interferometry. Proceedings of Fringe, Liège, 10-12 November 1999, 10-12.

[7] Catani, F., Farina, P., Moretti, S., Nico, G. and Strozzi, T. (2005) On the Application of SAR Interferometry to Geomorphological Studies: Estimation of Landform Attributes and Mass Movements. Geomorphology, 66, 119-131. https://doi.org/10.1016/j.geomorph.2004.08.012

[8] Strozzi, T., Farina, P., Corsini, A., Ambrosi, C., Thüring, M., Zilger, J., et al. (2005) Survey and Monitoring of Landslide Displacements by Means of L-Band Satellite SAR Interferometry. Landslides, 2, 193-201. https://doi.org/10.1007/s10346-005-0003-2

[9] Calabro, M.D., Schmidt, D.A. and Roering, J.J. (2010) An Examination of Seasonal Deformation at the Portuguese Bend Landslide, Southern California, Using Radar 
Interferometry. Journal of Geophysical Research: Earth Surface, 115, F02020. https://doi.org/10.1029/2009JF001314

[10] Schlögel, R., Doubre, C., Malet, J.P. and Masson, F. (2015) Landslide Deformation Monitoring with ALOS/PALSAR Imagery: A D-InSAR Geomorphological Interpretation Method. Geomorphology, 231, 314-330.

https://doi.org/10.1016/j.geomorph.2014.11.031

[11] Raucoules, D., de Michele, M. and Aunay, B. (2020) Landslide Displacement Mapping Based on ALOS-2/PALSAR-2 Data Using Image Correlation Techniques and SAR Interferometry: Application to the Hell-Bourg Landslide (Salazie Circle, La Réunion Island). Geocarto International, 35, 113-127. https://doi.org/10.1080/10106049.2018.1508311

[12] Ferretti, A., Prati, C. and Rocca, F. (2001) Permanent Scatterers in SAR Interferometry. IEEE Transactions on Geoscience and Remote Sensing, 39, 8-20. https://doi.org/10.1109/36.898661

[13] Even, M. and Schulz, K. (2018) InSAR Deformation Analysis with Distributed Scatterers: A Review Complemented by New Advances. Remote Sensing, 10, Article No. 744. https://doi.org/10.3390/rs10050744

[14] Hooper, A., Zebker, H., Segall, P. and Kampes, B. (2004) A New Method for Measuring Deformation on Volcanoes and Other Natural Terrains Using InSAR Persistent Scatterers. Geophysical Research Letters, 31, L23611.

https://doi.org/10.1029/2004GL021737

[15] Ciampalini, A., Raspini, F., Lagomarsino, D., Catani, F. and Casagli, N. (2016) Landslide Susceptibility Map Refinement Using PSInSAR Data. Remote Sensing of Environment, 184, 302-315. https://doi.org/10.1016/j.rse.2016.07.018

[16] Jiaxuan, H., Mowen, X. and Atkinson, P. M. (2020) Dynamic Susceptibility Mapping of Slow-Moving Landslides Using PSInSAR. International Journal of Remote Sensing, 41, 7509-7529. https://doi.org/10.1080/01431161.2020.1760398

[17] Wasowski, J. and Bovenga, F. (2014) Investigating Landslides and Unstable Slopes with Satellite Multi Temporal Interferometry: Current Issues and Future Perspectives. Engineering Geology, 174, 103-138. https://doi.org/10.1016/j.enggeo.2014.03.003

[18] Meisina, C., Zucca, F., Notti, D., Colombo, A., Cucchi, A., Savio, G., et al. (2008) Geological Interpretation of PSInSAR Data at Regional Scale. Sensors, 8, 7469-7492. https://doi.org/10.3390/s8117469

[19] Notti, D., Meisina, C. and Zucca, F. (2009) Analysis of PSInSAR ${ }^{\mathrm{m}}$ Data for Landslide Studies from Regional to Local Scale. Proceedings of Fringe Workshop, Frascati, 30 November-4 December 2009.

[20] Hastaoglu, K.O. (2016) Comparing the Results of PSInSAR and GNSS on Slow Motion Landslides, Koyulhisar, Turkey. Geomatics, Natural Hazards and Risk, 7, 786-803. https://doi.org/10.1080/19475705.2014.978822

[21] Oliveira, S.C., Zêzere, J.L., Catalão, J. and Nico, G. (2015) The Contribution of PSInSAR Interferometry to Landslide Hazard in Weak Rock-Dominated Areas. Landslides, 12, 703-719. https://doi.org/10.1007/s10346-014-0522-9

[22] Ciampalini, A., Bardi, F., Bianchini, S., Frodella, W., Del Ventisette, C., Moretti, S. and Casagli, N. (2014) Analysis of Building Deformation in Landslide Area Using Multisensory PSInSAR ${ }^{\mathrm{T}}$ Technique. International Journal of Applied Earth Observation and Geoinformation, 33, 166-180. https://doi.org/10.1016/j.jag.2014.05.011

[23] Ciampalini, A., Raspini, F., Frodella, W., Bardi, F., Bianchini, S. and Moretti, S. 
(2016) The Effectiveness of High-Resolution LiDAR Data Combined with PSInSAR Data in Landslide Study. Landslides, 13, 399-410. https://doi.org/10.1007/s10346-015-0663-5

[24] Mateos, R.M., Azañón, J.M., Roldán, F.J., Notti, D., Pérez-Peña, V., Galve, J.P., et al. (2017) The Combined Use of PSInSAR and UAV Photogrammetry Techniques for the Analysis of the Kinematics of a Coastal Landslide Affecting an Urban Area (SE Spain). Landslides, 14, 743-754. https://doi.org/10.1007/s10346-016-0723-5

[25] Meisina, C., Notti, D., Zucca, F., Ceriani, M., Colombo, A., Poggi, F., et al. (2013) The Use of PSInSAR ${ }^{\mathrm{Tm}}$ and SqueeSAR ${ }^{\mathrm{mm}}$ Techniques for Updating Landslide Inventories. In: Margottini, C., Canuti, P. and Sassa, K., Eds., Landslide Science and Practice, Springer, Berlin, Heidelberg, 81-87. https://doi.org/10.1007/978-3-642-31325-7_10

[26] Notti, D., Galve, J.P., Mateos, R.M., Monserrat, O., Lamas-Fernández, F., Fernández-Chacón, F., et al. (2015) Human-Induced Coastal Landslide Reactivation. Monitoring by PSInSAR Techniques and Urban Damage Survey (SE Spain). Landslides, 12, 1007-1014. https://doi.org/10.1007/s10346-015-0612-3

[27] Yazici, B.V. and Tunc Gormus, E. (2020) Investigating Persistent Scatterer InSAR (PSInSAR) Technique Efficiency for Landslides Mapping: A Case Study in Artvin Dam Area, in Turkey. Geocarto International, 1-19. https://doi.org/10.1080/10106049.2020.1818854

[28] Solari, L., Raspini, F., Del Soldato, M., Bianchini, S., Ciampalini, A., Ferrigno, F., et al. (2018) Satellite Radar Data for Back-Analysing a Landslide Event: The Ponzano (Central Italy) Case Study. Landslides, 15, 773-782. https://doi.org/10.1007/s10346-018-0952-x

[29] Liu, P., Li, Z., Hoey, T., Kincal, C., Zhang, J., Zeng, Q. and Muller, J.P. (2013) Using Advanced InSAR Time Series Techniques to Monitor Landslide Movements in Badong of the Three Gorges Region, China. International Journal of Applied Earth Observation and Geoinformation, 21, 253-264. https://doi.org/10.1016/j.jag.2011.10.010

[30] Khorrami, M., Abrishami, S., Maghsoudi, Y., Alizadeh, B. and Perissin, D. (2020) Extreme Subsidence in a Populated City (Mashhad) Detected by PSInSAR Considering Groundwater Withdrawal and Geotechnical Properties. Scientific Reports, 10, Article No. 111357. https://doi.org/10.1038/s41598-020-67989-1

[31] Makabayi, B., Musinguzi, M. and Otukei, J. R. (2021) Estimation of Ground Deformation in Landslide Prone Areas Using GPS: A Case Study of Bududa, Uganda. International Journal of Geosciences, 12, 213-232.

https://doi.org/10.4236/ijg.2021.123013

[32] Yagüe-Martínez, N., Prats-Iraola, P., Gonzalez, F. R., Brcic, R., Shau, R., Geudtner, D., et al. (2016) Interferometric Processing of Sentinel-1 TOPS Data. IEEE Transactions on Geoscience and Remote Sensing, 54, 2220-2234. https://doi.org/10.1109/TGRS.2015.2497902

[33] Babu, A. and Kumar, S. (2019) PSInSAR Processing for Volcanic Ground Deformation Monitoring over Fogo Island. Multidisciplinary Digital Publishing Institute Proceedings, 24, Article No. 3. https://doi.org/10.3390/IECG2019-06217

[34] Farr, T.G., Rosen, P.A., Caro, E., Crippen, R., Duren, R., Hensley, S., et al. (2007) The Shuttle Radar Topography Mission. Reviews of Geophysics, 45, RG2004. https://doi.org/10.1029/2005RG000183

[35] Azadnejad, S., Maghsoudi, Y. and Perissin, D. (2020) Evaluation of Polarimetric Capabilities of Dual Polarized Sentinel-1 and TerraSAR-X Data to Improve the 
PSInSAR Algorithm Using Amplitude Dispersion Index Optimization. International Journal of Applied Earth Observation and Geoinformation, 84, Article ID: 101950. https://doi.org/10.1016/j.jag.2019.101950

[36] Ferretti, A., Prati, C. and Rocca, F. (2000) Analysis of Permanent Scatterers in SAR Interferometry. IEEE 2000 International Geoscience and Remote Sensing Symposium, Honolulu, 24-28 July 2000, 761-763. https://doi.org/10.1109/IGARSS.2000.861695

[37] Colesanti, C., Ferretti, A., Prati, C. and Rocca, F. (2003) Monitoring Landslides and Tectonic Motions with the Permanent Scatterers Technique. Engineering Geology, 68, 3-14. https://doi.org/10.1016/S0013-7952(02)00195-3

[38] Salvi, S., Atzori, S., Tolomei, C., Allievi, J., Ferretti, A., Rocca, F., et al. (2004) Inflation Rate of the Colli Albani Volcanic Complex Retrieved by the Permanent Scatterers SAR Interferometry Technique. Geophysical Research Letters, 31, L12606. https://doi.org/10.1029/2004GL020253

[39] Ferretti, A., Prati, C. and Rocca, F. (1999) Permanent Scatterers in SAR Interferometry. IEEE 1999 International Geoscience and Remote Sensing Symposium, Florence, 22-24 September 1999, 1528-1530. https://doi.org/10.1117/12.373150

[40] Hooper, A., Bekaert, D., Spaans, K. and Arıkan, M. (2012) Recent Advances in SAR Interferometry Time Series Analysis for Measuring Crustal Deformation. Tectonophysics, 514, 1-13. https://doi.org/10.1016/j.tecto.2011.10.013

[41] Hooper, A. (2008) A Multi-Temporal InSAR Method Incorporating Both Persistent Scatterer and Small Baseline Approaches. Geophysical Research Letters, 35, L16302. https://doi.org/10.1029/2008GL034654

[42] Hooper, A., Segall, P. and Zebker, H. (2007) Persistent Scatterer Interferometric Synthetic Aperture Radar for Crustal Deformation Analysis, with Application to Volcán Alcedo, Galápagos. Journal of Geophysical Research: Solid Earth, 112, B07407. https://doi.org/10.1029/2006JB004763

[43] Gonnuru, P. and Kumar, S. (2018) PsInSAR Based Land Subsidence Estimation of Burgan Oil Field Using TerraSAR-X Data. Remote Sensing Applications: Society and Environment, 9, 17-25. https://doi.org/10.1016/j.rsase.2017.11.003

[44] Ab Latip, A. S., Matori, A., Aobpaet, A. and Din, A. H. M. (2015) Monitoring of Offshore Platform Deformation with Stanford Method of Persistent Scatterer (StaMPS). 2015 International Conference on Space Science and Communication, Langkawi, 10-12 Auguest 2015, 79-83. https://doi.org/10.1109/IconSpace.2015.7283785

[45] Sun, Q., Zhang, L., Ding, X.L., Hu, J., Li, Z.W. and Zhu, J.J. (2015) Slope Deformation Prior to Zhouqu, China Landslide from InSAR Time Series Analysis. Remote Sensing of Environment, 156, 45-57. https://doi.org/10.1016/j.rse.2014.09.029

[46] Kitutu, M. G., Muwanga, A., Poesen, J. and Deckers, J. A. (2009) Influence of Soil Properties on Landslide Occurrences in Bududa District, Eastern Uganda. African Journal of Agricultural Research, 4, 611-620.

[47] Claessens, L., Knapen, A., Kitutu, M. G., Poesen, J. and Deckers, J. A. (2007) Modelling Landslide Hazard, Soil Redistribution and Sediment Yield of Landslides on the Ugandan Footslopes of Mount Elgon. Geomorphology, 90, 23-35.

https://doi.org/10.1016/j.geomorph.2007.01.007

[48] Kitutu, M. G., Muwanga, A., Poesen, J. and Deckers, S. (2011) Farmer's Perception on Landslide Occurrences in Bududa District, Eastern Uganda. African Journal of Agricultural Research, 6, 7-18.

[49] Mugagga, F., Kakembo, V. and Buyinza, M. (2012) A Characterisation of the Physi- 
cal Properties of Soil and the Implications for Landslide Occurrence on the Slopes of Mount Elgon, Eastern Uganda. Natural hazards, 60, 1113-1131.

https://doi.org/10.1007/s11069-011-9896-3

[50] Knapen, A., Kitutu, M. G., Poesen, J., Breugelmans, W., Deckers, J. and Muwanga, A. (2006) Landslides in a Densely Populated County at the Footslopes of Mount Elgon (Uganda): Characteristics and Causal Factors. Geomorphology, 73, 149-165. https://doi.org/10.1016/j.geomorph.2005.07.004

[51] Staudt, M., Kuosmanen, E., Babirye, P. and Lugaizi, I. (2014) The Bududa Landslide of 1 March 2010. Special Paper No. 56, Geological Survey of Finland, Espoo, 373-384.

[52] Nakileza, B. R. and Tushabe, H. (2018) Determinants of Revegetation on Landslide Scars in an Agro-Based Socio-Ecological System in Bududa, Uganda. International Journal of Biodiversity and Conservation, 10, 444-452.

https://doi.org/10.5897/IJBC2018.1220

[53] Nelson, O., Kassim, A., Yunusa, G. H. and Talib, Z. A. (2015) Modelling the Effect of Wind Forces on Landslide Occurrence in Bududa District, Uganda. Journal Teknologi, 77, 35-42. https://doi.org/10.11113/jt.v77.6392

[54] Mugagga, F., Kakembo, V. and Buyinza, M. (2012) Land Use Changes on the Slopes of Mount Elgon and the Implications for the Occurrence of Landslides. Catena, 90, 39-46. https://doi.org/10.1016/j.catena.2011.11.004

[55] Van Eynde, E., Dondeyne, S., Isabirye, M., Deckers, J. and Poesen, J. (2017) Impact of Landslides on Soil Characteristics: Implications for Estimating Their Age. Catena, 157, 173-179. https://doi.org/10.1016/j.catena.2017.05.003 